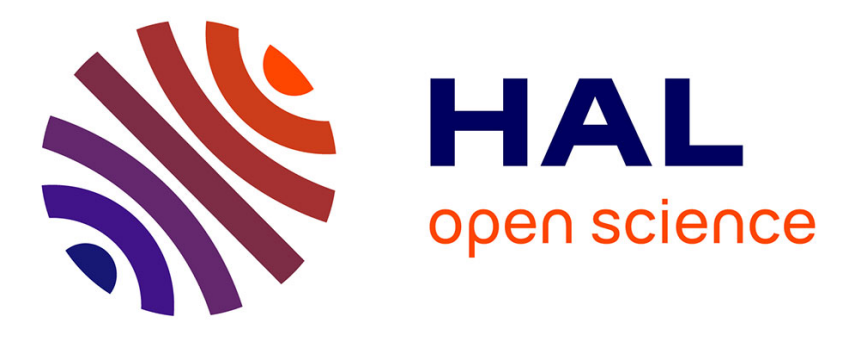

\title{
Magnetic structure of a slow spreading ridge segment: Insights from near-bottom magnetic measurements on board a submersible
}

Chie Honsho, J. Dyment, Kensaku Tamaki, Morgane Ravilly, Hélène Horen, Pascal Gente

\section{To cite this version:}

Chie Honsho, J. Dyment, Kensaku Tamaki, Morgane Ravilly, Hélène Horen, et al.. Magnetic structure of a slow spreading ridge segment: Insights from near-bottom magnetic measurements on board a submersible. Journal of Geophysical Research: Solid Earth, 2009, 114, pp.B05101. 10.1029/2008JB005915 . insu-00446462

\section{HAL Id: insu-00446462 \\ https://hal-insu.archives-ouvertes.fr/insu-00446462}

Submitted on 15 Feb 2011

HAL is a multi-disciplinary open access archive for the deposit and dissemination of scientific research documents, whether they are published or not. The documents may come from teaching and research institutions in France or abroad, or from public or private research centers.
L'archive ouverte pluridisciplinaire HAL, est destinée au dépôt et à la diffusion de documents scientifiques de niveau recherche, publiés ou non, émanant des établissements d'enseignement et de recherche français ou étrangers, des laboratoires publics ou privés. 


\title{
Magnetic structure of a slow spreading ridge segment: Insights from near-bottom magnetic measurements on board a submersible
}

\author{
Chie Honsho, ${ }^{1}$ Jérôme Dyment, ${ }^{2}$ Kensaku Tamaki, ${ }^{1}$ Morgane Ravilly, ${ }^{3,4}$ Hélène Horen, ${ }^{5,6}$ \\ and Pascal Gente ${ }^{3,7}$
}

Received 29 June 2008; revised 18 January 2009; accepted 18 February 2009; published 8 May 2009.

[1] Near-bottom magnetic measurements on board submersible Nautile were carried out on the Mid-Atlantic Ridge $21^{\circ} 40^{\prime} \mathrm{N}$ segment, and deep-sea geomagnetic vector anomalies along 19 dive tracks were obtained by applying the processing method for shipboard threecomponent magnetometer data. A forward modeling technique using short-wavelength components of the anomalies arising from local topography and vertical motion of the submersible was designed to estimate the absolute magnetization intensity of the seafloor. In the vicinity of the spreading axis a considerable number of magnetization estimations are reliably confirmed by the high correlation between observed and modeled anomalies, whereas less reliable estimations are obtained off-axis, probably because the sediment buries the basement topography. The natural remanent magnetization (NRM) measured on basalt samples collected during these dives is compared with the magnetization from anomalies. Though both results give a similar range of magnetization intensity, no correlation is confirmed between them, possibly because the magnetization from anomalies represents laterally averaged seafloor magnetization, whereas the NRM has variations at the scale of individual pillow or lava pile. Equivalent magnetization inverted from the sea-surface magnetic anomalies shows axial magnetization increases significantly from the segment center to the segment ends. However, the results of eight dives conducted near the spreading axis at different locations along the segment show much less variation in magnetization intensity along the axis. We ascribe the high equivalent magnetization at segment ends to preferential serpentinization of peridotite near the segment ends and the associated formation of magnetite. The results of three across-axis transects composed of 15 dives running in the spreading direction can be consistently interpreted as recording geomagnetic paleointensity variations during the Brunhes epoch. Although magnetization lows are generally correspondent to periods of low paleointensity, they show deeper drop than predicted from the paleointensity variation.

Citation: Honsho, C., J. Dyment, K. Tamaki, M. Ravilly, H. Horen, and P. Gente (2009), Magnetic structure of a slow spreading ridge segment: Insights from near-bottom magnetic measurements on board a submersible, J. Geophys. Res., 114, B05101, doi:10.1029/2008JB005915.

\section{Introduction}

[2] Marine magnetic anomalies have made a great contribution to the establishment and evolution of the plate tectonic

\footnotetext{
${ }^{1}$ Frontier Research Center for Energy and Resources, School of Engineering, University of Tokyo, Tokyo, Japan.

${ }^{2}$ Institut de Physique du Globe de Paris, UMR7154, CNRS, Paris, France.

${ }^{3}$ Domaines Océaniques, UMR6538, Institut Universitaire Européen de la Mer, Université de Brest, CNRS, Plouzane, France.

${ }^{4}$ Now at CREOCEAN, La Rochelle, France.

${ }^{5}$ Laboratoire de Géologie, UMR8538, Ecole Normale Supérieure, CNRS, Paris, France.

${ }^{6}$ Dynamique des Systèmes Anthropisés, JE2532, Université de Picardie Jules Verne, Amiens, France.

${ }^{7}$ Université Européenne de Bretagne, Bretagne, France.

Copyright 2009 by the American Geophysical Union. 0148-0227/09/2008JB005915\$09.00
}

theory [Vine and Matthews, 1963] and our understanding of the surface motion of the Earth since $180 \mathrm{Ma}$. Many recent studies on marine magnetic anomalies have focused on aspects other than the magnetic lineations associated with reversals of the geomagnetic field and have proposed various constraints and models on the magnetic structure of the oceanic crust, together with a diverse range of approaches from satellite magnetic anomalies to rock samples collected by dredge, to submersible studies and crustal drilling, and ophiolite studies. Extensive surveys on mid-ocean ridges have revealed detailed characteristics of marine magnetics, such as the decay of magnetization with time [Irving et al., 1970; Johnson and Atwater, 1977; Macdonald, 1977], the presence of a narrow and strong magnetic anomaly on the axis known as the central anomaly magnetic high (CAMH) [Klitgord, 1976], short-wavelength variations within a period 
of constant polarity [Blakely, 1974; Cande and LaBrecque, 1974; Tivey and Johnson, 1993; Gee et al., 1996; Lee et al., 1996; Gee et al., 2000; Pouliquen et al., 2001], and substantial along-axis variations related to the ridge segmentation [Sempere, 1991; Pariso et al., 1996; Gee and Kent, 1997; Ravilly et al., 1998]. Many of these findings have been achieved with the development of techniques to measure the magnetic field variations at a higher spatial resolution, i.e., near-bottom surveys. Other than deep-tow magnetic survey utilized in many of the studies cited above, nearbottom magnetic measurement using a deep-sea submersible is also an effective means to obtain high-resolution magnetic data. The advantage of submersible survey is the extreme proximity of the observation point to the magnetic source, that can provide direct information on the magnetization of the shallow part of the oceanic crust. Such near-bottom magnetic data were collected using submersible Nautile in the Mid-Atlantic Ridge (MAR) $21^{\circ} 40^{\prime} \mathrm{N}$ segment (Figure 1a), during the TAMMAR cruise by R/V Nadir in May 1996 [Gente et al., 1996]. The 19 dive surveys conducted in the segment are numbered from 02 to 20 in Figures $1 \mathrm{~b}$ and $1 \mathrm{~d}$. The traverses range from 2.5 to $6.0 \mathrm{~km}$ long, at an altitude varying from 2 to $20 \mathrm{~m}$ above the seafloor. Fifteen dives constitute three long $\mathrm{E}-\mathrm{W}$ transects of the ridge axis, located at the segment center (dives 06, 03, 02 and 04), near the segment southern end (dives 12,13,11 and 15) and in an intermediate position (dives 09, 08, 10, 16, 17, 05 and 07). The remaining four dives were devoted to complementary exploration along the inner valley floor (dives 20, 19, 18 and 14). After initial processing of the near-bottom magnetic data, we successfully obtained the three components of the geomagnetic field along these tracks. A forward modeling technique using short-wavelength component of the anomalies $(<\sim 250 \mathrm{~m})$ mainly produced by both the local topography and the vertical motion of the submersible was designed to estimate the absolute magnetization intensity of the seafloor. It is the refinement of a modeling technique used by Talwani et al. [1971]. Such absolute magnetization estimates are compared to the natural remanent magnetization (NRM) measured on basalt samples collected during these dives. For some dive surveys, long-wavelength components of the anomalies $(>\sim 300 \mathrm{~m})$ were utilized for the two-dimensional magnetic inversion. The along- and across-axis magnetization variations are discussed by combining results of the near-bottom magnetics, that reflect the shallow part of the magnetic layer, and the sea-surface magnetics, that integrate the effect of the whole magnetic layer. The across-axis variation in the central anomaly is examined in relation to deep-sea sediment records of the geomagnetic field intensity variation during the Brunhes period.

\section{Geologic Setting of MAR $21^{\circ} 40^{\prime} \mathbf{N}$ Segment}

2.1. Bathymetry and Sea-Surface Magnetics

[3] Figure 1a shows the bathymetry of the MAR between $20^{\circ} 30^{\prime} \mathrm{N}$ and $24^{\circ} \mathrm{N}$ collected during the 1991 FARASEADMA I cruise of R/V L'Atalante [Gente et al., 1995]. The MAR is segmented by nontransform discontinuities except for Kane Fracture Zone $\left(23^{\circ} 40^{\prime} \mathrm{N}\right)$ which represents a first-order discontinuity [Macdonald et al., 1988]. The MAR $21^{\circ} 40^{\prime} \mathrm{N}$ segment is a $75-\mathrm{km}$-long, highly magmatic ridge segment bounded on the north by a small $(\sim 6 \mathrm{~km})$ offset of the spreading axis and on the south by a $\sim 40 \mathrm{~km}$ offset. V-shaped bathymetric features can be traced from the southern end of the segment in the $\mathrm{N} 55^{\circ} \mathrm{E}$ and $\mathrm{N} 35^{\circ} \mathrm{W}$ directions, showing the southward propagation of this segment since chron 3 [Gente et al., 1995]. The full spreading rate in this area is $24 \mathrm{~km} / \mathrm{Ma}$ (calculated from NUVEL-1A [DeMets et al., 1994]), a typical value for slow spreading ridges.

[4] The topography of the MAR $21^{\circ} 40^{\prime} \mathrm{N}$ segment is shown in Figure 1b, projected onto a plane with the y axis running parallel to the spreading axis identified by the topographic low (in the $\mathrm{N} 12^{\circ} \mathrm{E}$ direction). The median valley is well developed and its depth is about $3100 \mathrm{~m}$ at the segment center and increases toward the segment ends to about $3800 \mathrm{~m}$. In the flanking highs two pairs of major topographic highs are recognized: one is at the segment center and just beyond the axial valley walls, as indicated in Figure $1 \mathrm{~b}$ by "W1" on the western flank and "E1" on the eastern flank. These hills are almost symmetrical in shape and depth, shallowing up to $2300 \mathrm{~m}$. Another pair is at about $10 \mathrm{~km}$ away from the axis and about $10 \mathrm{~km}$ south of the segment center, indicated by "W2" and "E2" in Figure 1b. The western hill "W2" is shallower than $1850 \mathrm{~m}$, the shallowest in the segment, and the eastern one "E2" shallows up to $1950 \mathrm{~m}$.

[5] The sea-surface magnetic data collected in 1991 during the FARA-SEADMA I cruise were completed during the TAMMAR cruise to get a $\sim 3 \mathrm{~km}$ spacing interval between profiles, allowing a grid $(1 \mathrm{~km})$ to be computed (Figure 1c). This sea-surface magnetic anomaly grid was inverted to obtain an equivalent magnetization distribution in a source layer of constant thickness $(500 \mathrm{~m})$ whose upper boundary is constrained by the bathymetry [Parker and Huestis, 1974; Macdonald et al., 1980]. The source layer magnetization is assumed uniform with depth and parallel to the geocentric axial dipole field (inclination $=38.4^{\circ}$ ). To ensure convergence during the inversion, we applied a cosine-tapered low-pass

Figure 1. (a) Location of the TAMMAR cruise survey area. The bathymetric data were collected during the 1991 FARASEADMA I cruise by R/V L'Atalante [Gente et al., 1995]. Kane Fracture Zone and major ridge segments are shown by thick lines. (b) Bathymetry of the MAR $21^{\circ} 40^{\prime} \mathrm{N}$ segment. Data were projected onto the Cartesian coordinates of the unit in $\mathrm{km}$, with the y axis parallel to the axial direction $\left(\mathrm{N} 12^{\circ} \mathrm{E}\right)$. Contour interval is $100 \mathrm{~m}$. Position of the spreading axis is shown by a bold broken line running along $\mathrm{x}=0$. Dive tracks are shown by thick lines with the dive numbers. Major topographic highs, called W2, W1, E1, and E2, are bounded by thin broken lines (those bounding W2 and E2 are along $2300 \mathrm{~m}$ contours, and those bounding W1 and E1 (mostly) are along $2500 \mathrm{~m}$ contours). (c) Total intensity anomalies over the segment. Survey tracks of the TAMMAR cruise and the 1991 FARA-SEADMA I cruise are shown by broken and dotted lines, respectively. Contour interval is $50 \mathrm{nT}$. (d) Equivalent magnetization distribution computed for a constant-thickness source layer of $500 \mathrm{~m}$ whose upper boundary is defined by the bathymetry. Contour interval is $2 \mathrm{~A} / \mathrm{m}$. Locations of dive tracks and major topographic highs shown in the bathymetric map are also superimposed. 

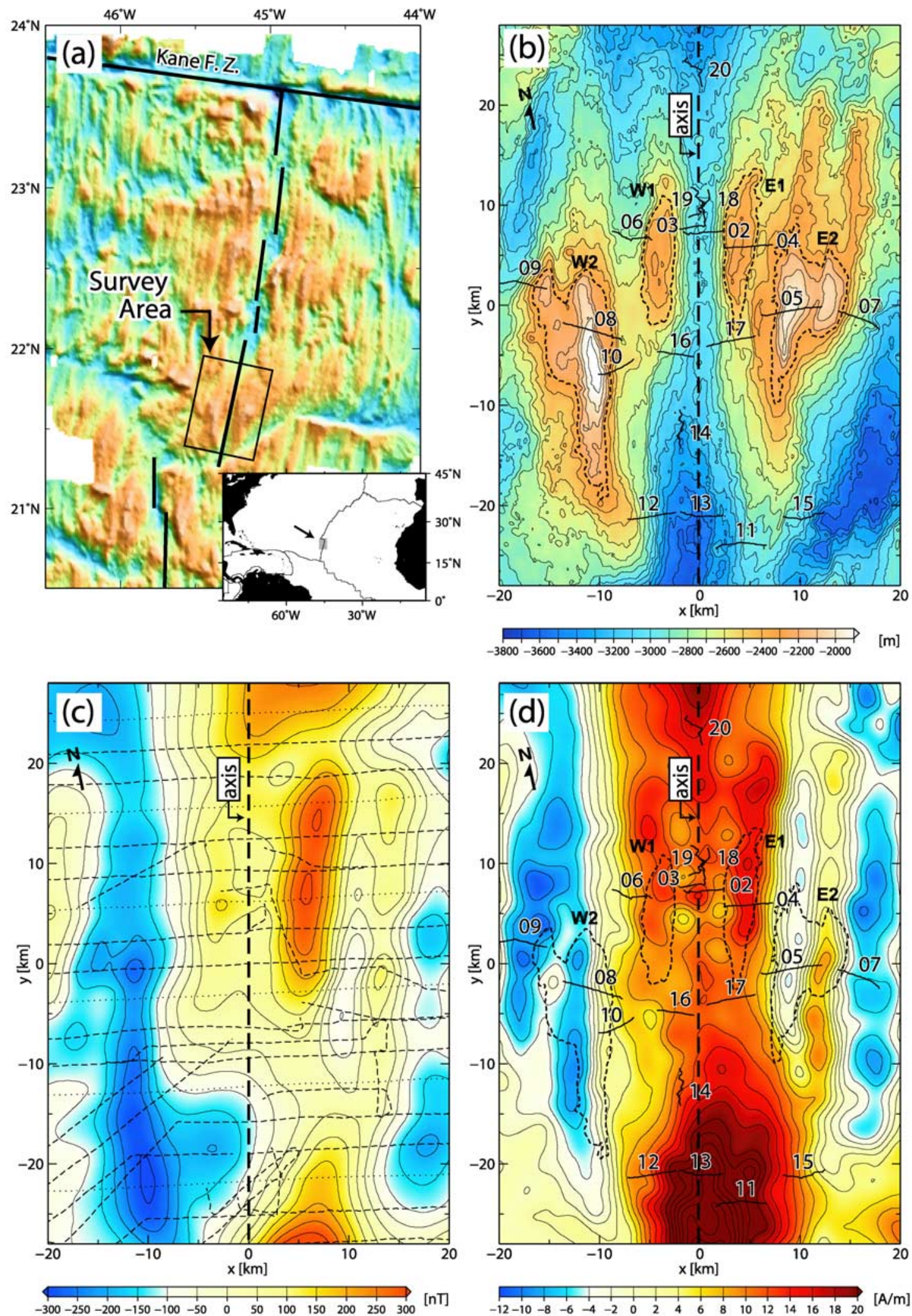

Figure 1 
filter beginning at a wave number $k=1.82 \mathrm{rad} \cdot \mathrm{km}^{-1}$ (wavelength $\lambda=2 \pi k^{-1}=3.45 \mathrm{~km}$ ) and reaching zero at $k=2.21 \mathrm{rad} \cdot \mathrm{km}^{-1}(\lambda=2.84 \mathrm{~km})$. Figure $1 \mathrm{~d}$ shows the solution of the magnetic inversion. Negative values represent magnetization in the reversed direction. No annihilator has been added because the positive and negative amplitudes of the resulting solution are approximately equal, except for remarkably strong positives near the segment ends (discussed later). The Brunhes-Matuyama (BM) boundary is represented by the magnetization transitions located at $\sim 11 \mathrm{~km}$ in the west and at $\sim 8 \mathrm{~km}$ in the east of the axis. The Jaramillo chron appears as a clear ridge-parallel lineation on the eastern flank at $\sim 12 \mathrm{~km}$ from the axis. In contrast, its conjugate is more difficult to identify on the western flank and appears as a short and oblique lineation running between dives 09 and 08 . The magnetic lineations up to anomaly $2 \mathrm{~A}$ young were identified, though they are beyond the range of Figure 1d and not shown, giving the average full spreading rate of $23.6 \mathrm{~km} / \mathrm{Ma}$ for the period.

[6] The most pronounced feature of Figures 1c and 1d is the large variation of both the axial magnetic anomaly amplitude and the corresponding equivalent magnetization along the axis. The equivalent magnetization varies from about $10 \mathrm{~A} / \mathrm{m}$ near the segment center $(\mathrm{y}=\sim 5)$ to $\sim 20 \mathrm{~A} / \mathrm{m}$ near the northern segment end $(y=\sim 30)$ and more than $30 \mathrm{~A} / \mathrm{m}$ to the southern segment end. Similar variations associated with ridge axis segmentation have been observed in many MAR segments [Tivey et al., 1993; Weiland and Macdonald, 1993; Pockalny et al., 1995; Pariso et al., 1995; Weiland et al., 1996; Tivey and Tucholke, 1998] and confirmed to be systematic over 25 segments of the MAR between 20 and $40^{\circ} \mathrm{N}$ [Ravilly et al., 1998]. They are also widely recognized in other spreading centers [e.g., Hey et al., 1986; Sempere, 1991; Lee et al., 1996]. The origin of such variations is still debated. Possible explanations include (1) the presence of Fe-Ti-rich basalt as a result of shallow-level crystal fractionation in small magma bodies, which would occur at ridge discontinuities with reduced magmatic supply [Christie and Sinton, 1981; Weiland and Macdonald, 1993; Weiland et al., 1996; Horen and Fleutelot, 1998]; (2) the presence of secondary magnetite as a result of serpentinization of outcropping peridotites at segment end discontinuities [Pockalny et al., 1995; Pariso et al., 1996]; (3) thickness variation of the magnetic source layer [Grindlay et al., 1992; Tivey et al., 1993; Pariso et al., 1996]; and (4) decrease of magnetization at segment center related to more pervasive faulting and hydrothermal activity [Tivey and Johnson, 1987; Wooldridge et al., 1992]. The association of iron-rich basalt with high-amplitude magnetic anomalies has been relatively well documented in the vicinity of hot spots [Vogt and Byerly, 1976; Vogt, 1979] and at fast spreading center discontinuities [Sempere, 1991], and a relationship between enhanced iron content and high remanent magnetization has been reported on the fast spreading East Pacific Rise [Gee and Kent, 1997] and the intermediate spreading North Fiji Basin Central Ridge [Horen and Fleutelot, 1998]. On the MAR, the analyses of 25 segments between 20 and $40^{\circ} \mathrm{N}$ [Ravilly et al., 1998] as well as 3-D thermomagnetic modeling of a segment [Gac et al., 2003] favor the conjugate effects of higher degree of fractionation in the basalt and serpentinization of shallow or outcropping peridotite at segment ends, although the relative importance of these processes cannot be evaluated unambiguously from sea-surface magnetic data alone.

[7] Beyond these variations of the axial magnetic anomaly amplitude, the sea-surface inversion also reveals significant variations in the shape of the central anomaly along the ridge segment. The central anomaly is marked by a single broad arch at the segment ends, whereas it contains secondary anomalies in the middle part of the segment: the northern half of the segment (from $y=2$ to 20 ) is characterized by three lobes in the central anomaly, and the southern half (from $y=$ -15 to 2 ) has a flatter shape of the central anomaly though it still has a peak on the spreading axis. The central lobe corresponds to the $\mathrm{CAMH}$, a narrow and linear magnetic anomaly observed on many spreading centers [Klitgord, 1976], and is associated with the axial valley floor and the neovolcanic zone as defined by Nautile observations. Despite sparser data sets, the observation of three lobes at segment centers and a broad arch at segment ends has been generalized to other MAR segments between 20 and $40^{\circ} \mathrm{N}$ [Ravilly, 1999].

\subsection{Evolution Model Since Jaramillo}

[8] The evolution of the MAR $21^{\circ} 40^{\prime} \mathrm{N}$ segment is generally described by the nearly symmetric spreading and the continuous southward propagation of the ridge axis since chron 3 (4.5 Ma) [Gente et al., 1995]. A closer inspection of the magnetic inversion result (Figure 1d) gives more details on the recent spreading history: (1) the Brunhes-Matuyama boundary is $\sim 11 \mathrm{~km}$ from the axis on the western flank but only $\sim 8 \mathrm{~km}$ from the axis on the eastern flank, resulting in $\sim 3 \mathrm{~km}$ more crust accreted to the west than the east during the Brunhes period; (2) the Jaramillo anomaly is clearly shown on the eastern flank, whereas it is difficult to recognize on the western flank. The latter observation indicates the occurrence of a small ridge jump or a short period of strong asymmetric spreading leading to the accretion of almost all the crust produced during the Jaramillo period to the eastern flank. The Jaramillo anomaly on the eastern flank ( $\sim 3 \mathrm{~km}$ in width) is sufficiently wide enough to correspond to a doubled lineation $(1.89 \mathrm{~km}$ at the full rate).

[9] As for the asymmetry during the Brunhes period, let us consider the two pairs of abyssal hills on both sides of the axis (Figure 1b). The inner abyssal hills W1 and E1 are located at almost the same distance from the axis, whereas the outer abyssal hill W2 on the western flank is further away from the axis than E2 on the eastern flank. The difference is accommodated by a bathymetric low $2.5-3 \mathrm{~km}$ wide between the hills W2 and W1 on the western flank which is not observed on the eastern flank. We interpret the bathymetric low as a paleospreading axis trapped on the western flank by a small eastward ridge jump. Considering the distance to the present axis and the width of the bathymetric low, this small ridge jump of about $1.8 \mathrm{~km}$ would have occurred at $0.45 \mathrm{Ma}$. The amplitude of the ridge jump, $1.8 \mathrm{~km}$, means that it corresponds to a relocation of the neovolcanic zone within the axial valley. A submersible survey conducted in the bathymetric low (dive 06) shows grabens trending along the axial direction on the valley floor and many outward facing normal faults along the eastern wall. These observations reinforce our interpretation of a spreading axis relocation by an eastward jump.

[10] The preferred evolution model includes a small ridge jump at $0.45 \mathrm{Ma}$ and a second ridge jump at $1.0 \mathrm{Ma}$ (Figure 2). Because directions of the ridge jumps are oppo- 
(a)

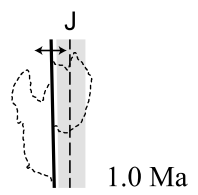

(b)

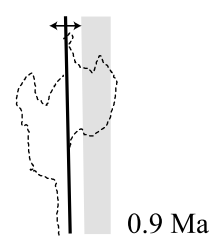

(c)

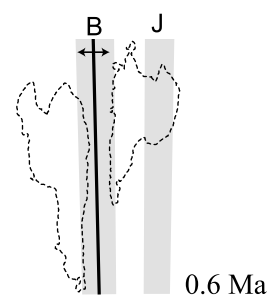

(d)

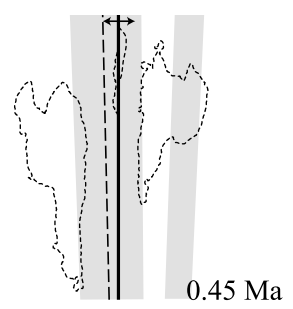

(e)
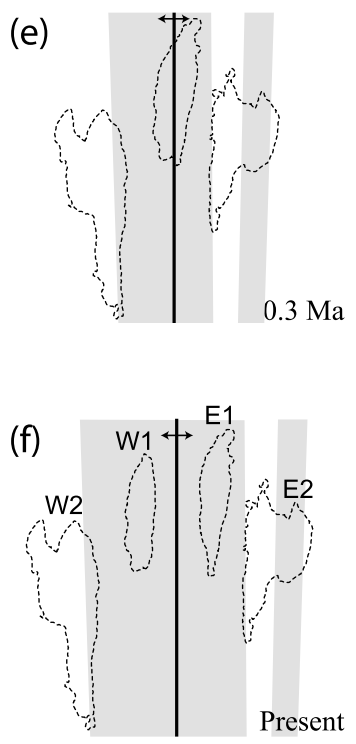

Figure 2. Evolution model of the MAR $21^{\circ} 40^{\prime} \mathrm{N}$ segment since 1.0 Ma. The active spreading axis is shown by bold lines with arrows, and the abandoned axis is shown by broken lines. Major topographic highs shown in Figures $1 \mathrm{~b}$ and $1 \mathrm{~d}$ are surrounded by thin broken lines. Gray shades represent the positively magnetized crust. Small ridge jumps occur at $1.0 \mathrm{Ma}$ (to the west by $2.0 \mathrm{~km}$ ) and at $0.45 \mathrm{Ma}$ (to the east by $1.8 \mathrm{~km})$. site, the total amount of crust accreted during the last $1 \mathrm{Ma}$ does not significantly differ between both sides. As for older chrons no evidence of a persistent asymmetric spreading has been found [Gente et al., 1995]. That may mean such an alternating asymmetric spreading at a short timescale commonly occur but the asymmetry is almost canceled out at a longer timescale $(>\sim 1 \mathrm{Ma})$. If the abyssal hills reflect pulses of volcanic activity [Kappel and Ryan, 1986], then the first pulse may have generated most of the older topographic highs, the whole of "E2" and the eastern part of "W2" (Figures $2 \mathrm{a}-2 \mathrm{c}$ ). The ridge jump at 0.45 Ma may have been triggered by the second pulse of volcanic activity which has generated the younger topographic highs "E1" and "W1" (Figures $2 \mathrm{~d}$ and $2 \mathrm{e}$ ). The valley floor of the fossil axis is distinctly limited to the east by the westward facing scarp near the segment center (Figure 1b); however, this scarp progressively disappears southward and the fossil axis deepens continuously toward the present axis, forming a broad $\mathrm{V}$-shaped axial valley. The ridge jump may not have occurred along all the segment at once but seems to have initiated near the present segment center and propagated southward.

\section{Data Acquisition and Initial Processing}

[11] A deep-sea three-component magnetometer developed by the Ocean Research Institute of the University of Tokyo [Sayanagi et al., 1995] was installed on Nautile. The magnetometer system consists of two units: a sensor unit with 3 orthogonally arranged fluxgate sensors and a gyro unit with data memory and vertical gyrocompasses to measure the instrument attitude. The magnetometer system logged the three components of the magnetic field and the vertical attitude of the instrument (pitch and roll) every second, and the Nautile data system recorded heading, pitch, depth and altitude every two seconds. Heading, depth and altitude data from Nautile were interpolated and compiled with the data from the magnetometer to produce a complete data set with a sampling interval of one second.

[12] The observed three-component magnetic data were first corrected for the magnetic field produced by Nautile using the processing method for shipboard three-component magnetometer (STCM) data [Isezaki, 1986] adapted for the deep-sea submersible (see auxiliary material). ${ }^{1}$ We used data collected while the submersible was descending and had several $360^{\circ}$ rotations for the correction. The International Geomagnetic Reference Field (IGRF) was subtracted from the corrected data to obtain the geomagnetic vector anomalies. The uncertainties associated with resulting anomalies depend on how this correction works, because the error of the correction is generally much larger than that of measurement instruments. The correction was performed for each dive giving the standard errors of 196-539 nT.

[13] The subsequent two-dimensional analyses require the data projected onto a straight line. For the purpose of the forward modeling analysis using short-wavelength component of the anomalies a line closest to each dive track was chosen as an individual projection line: because the submersible was generally heading normal to the strike of the local structures, the assumption of two-dimensionality inherent in

\footnotetext{
${ }^{1}$ Auxiliary materials are available with the full article. doi:10.1029/ 2008JB005915.
} 


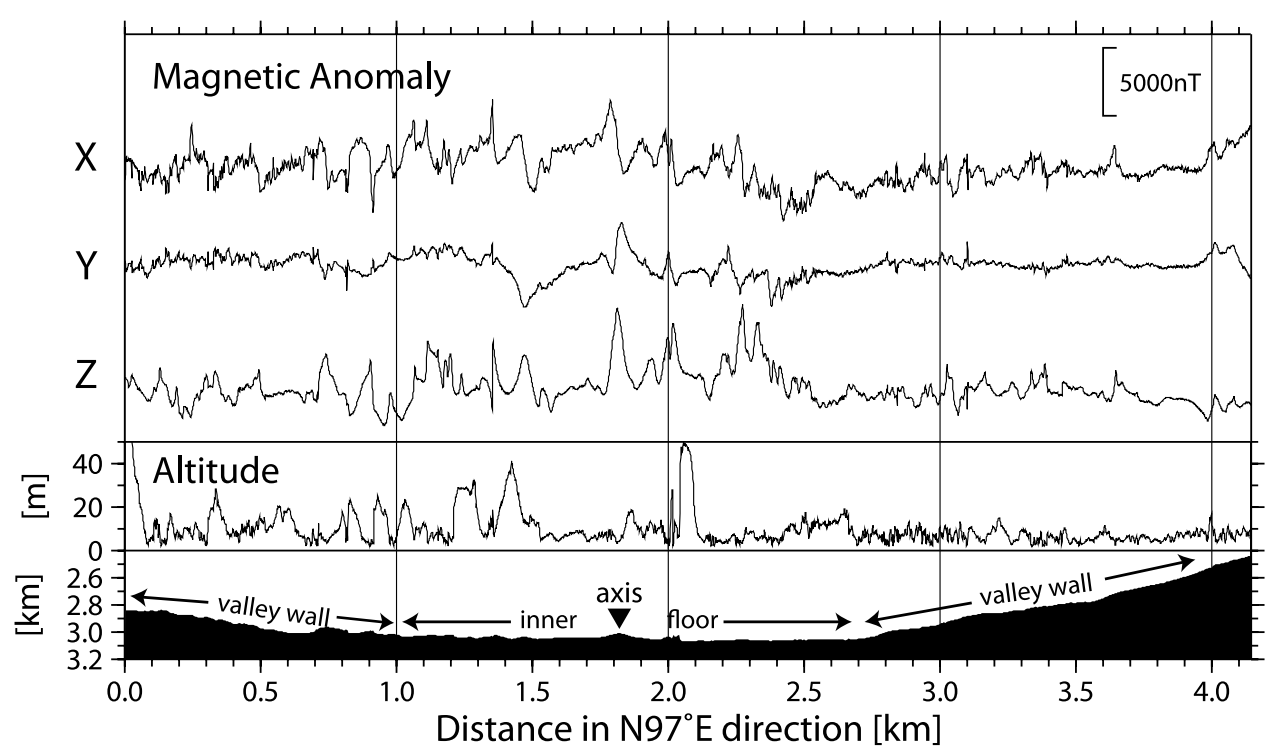

Figure 3. An example of the deep-sea geomagnetic vector anomalies obtained after the initial processing (dive 02, crossing the ridge axis near the segment center). The observed raw data are corrected for the magnetic field produced by the submersible, and the IGRF are subtracted. Altitude of the submersible and bathymetry are shown together. The dive track is projected onto a straight line of $\mathrm{N} 97^{\circ} \mathrm{E}$, and the direction of the $\mathrm{X}, \mathrm{Y}$, and $\mathrm{Z}$ components of the magnetic anomaly is defined as the direction of the projection line, $90^{\circ}$ clockwise from it, and downward, respectively.

the analysis is locally best satisfied by having the projection lines along dive tracks. The data were then resampled at an interval of $1 \mathrm{~m}$, which is approximately comparable to the sampling interval (1 second) and the submersible's speed ( $\sim 2$ knots). On the other hand, when utilized for the inversion analysis using long-wavelength component produced by the topographic and magnetic structure at a large scale, the data were projected along the spreading direction $\left(\mathrm{N} 102^{\circ} \mathrm{E}\right)$ considering the regional two-dimensionality.

[14] Figure 3 shows an example of the resulting geomagnetic vector anomalies after correction, along a projection line trending $\mathrm{N} 97^{\circ} \mathrm{E}$ that is the closest direction to the actual track (dive 02, crossing the spreading axis near the center of the segment; see Figure 1b). The directions of the X, Y and Z components of the magnetic anomaly are defined as those of the projection line, $90^{\circ}$ clockwise from it, and downward, respectively; the horizontal coordinates fixed to the projection direction were preferred to the geodetic coordinates (i.e., the northward and eastward axes), because they have more substantial meaning in the subsequent two-dimensional analyses as the variable $(\mathrm{X})$ and invariable $(\mathrm{Y})$ directions. The $\mathrm{Y}$ component actually has some variations, meaning the structure is not exactly two-dimensional. However, compared with the $\mathrm{X}$ and $\mathrm{Z}$ components the $\mathrm{Y}$ component can be remarked to have less variation at short wavelengths (from several ten to a few hundred meters), that is mainly produced by the local topography and vertical motion of the submersible.

\section{Analysis Method}

\subsection{Forward Modeling Analysis}

\subsubsection{Modeling of Short-Wavelength Variation}

[15] We attempted to simulate the short-wavelength signal by computing the magnetic field along the dive paths pro- duced by the uniformly magnetized seafloor (Figure 4). The intensity and direction of the magnetization were assumed to be $1 \mathrm{~A} / \mathrm{m}$ and parallel to the geocentric axial dipole field. We used the calculation algorithm developed by Talwani and Heirtzler [1964], presenting the expression of magnetic anomalies produced by a single side of a two-dimensional polygonal body. In the case of a half-infinite magnetic source whose upper boundary is constrained by the observed topog-

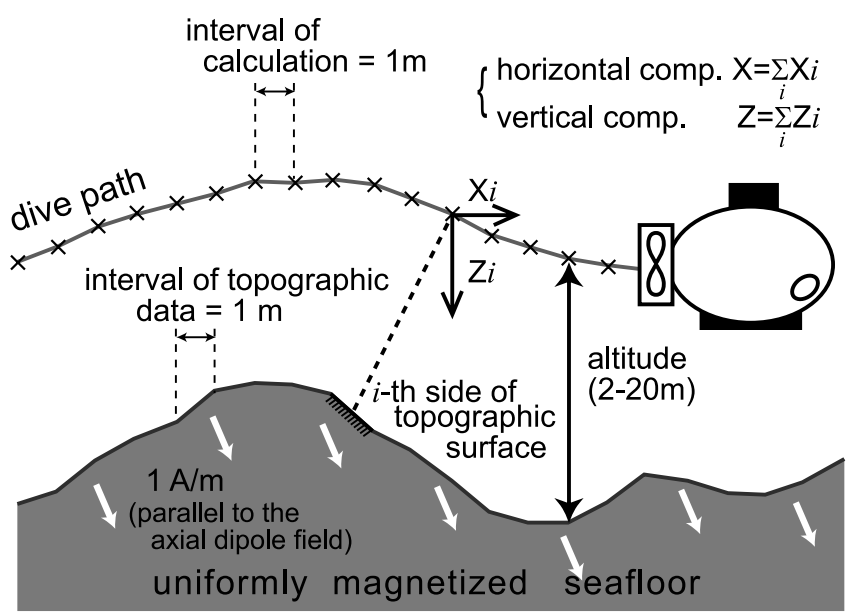

Figure 4. A sketch of the calculation of magnetic anomalies caused by a half-infinite, uniformly magnetized layer whose upper boundary is constrained by the seafloor topography. The horizontal (X) and vertical (Z) components of the magnetic anomaly are obtained each $1 \mathrm{~m}$ along dive paths by summing up anomalies due to each side of the topographic surface. The calculation algorithm of Talwani and Heirtzler [1964] was used. 




Figure 5. An example of synthetic magnetic anomalies (part of dive 02) calculated for different values of the magnetic layer thickness. A band-pass filter between 18 and $300 \mathrm{~m}$ was applied.

raphy, magnetic anomalies at each calculation point are obtained by summing up the magnetic anomalies due to each side of the topographic surface. If any lower boundary of the magnetic layer is considered (i.e., magnetic layer of a finite thickness) the magnetic anomalies produced by the lower boundary relief are calculated by the same procedure and then added. The horizontal and vertical components of the magnetic anomaly are calculated at an horizontal interval of $1 \mathrm{~m}$. Bathymetric data, sampled at the same interval, are based on depth (pressure) and altitude data of the submersible. To simulate observed anomalies on such a small scale as a meter, the geometry among the depth and altitude sensors and the magnetic sensor set in the submersible was properly taken into consideration.

[16] To remove long-wavelength variations and spiky noises a band-pass filter between 18 and $300 \mathrm{~m}$ was applied to both synthetic and observed profiles before comparison.
Concerning such short-wavelength variations, the calculated magnetic anomalies are not affected by the assumption of magnetic layer thickness as long as it is more than $\sim 100 \mathrm{~m}$ (Figure 5). The synthetic profile assuming a half-infinite source layer, that was adopted in the subsequent analyses, virtually represents the synthetic anomalies when the magnetization is uniform in the shallow ( $100 \mathrm{~m}$ below seafloor) part of crust, presupposing that in a deeper part the magnetization does not have more significant short-wavelength variations than what the topographic relief produces.

\subsubsection{Estimation of Absolute Magnetization}

[17] Figure 6a shows an example of the comparison between synthetic and observed anomalies (for dive 02), after the band-pass filter was applied. In spite of the idealized assumption of two-dimensional topography, the synthetic anomalies successfully simulate the observed profiles for both the $\mathrm{X}$ and $\mathrm{Z}$ components.

Figure 6. (a) Comparison between observed (solid lines) and synthetic (dashed lines) vector anomalies for dive 02 . The dots on the top indicate the center positions of 61 overlapping small segments clipped by the sliding window (256 m wide, each $64 \mathrm{~m}$ ), as well as the locations where the magnetization intensity is estimated. (b) Ratio, coherency, and phase calculated for each set of the clipped segments of the synthetic and observed profiles. Reliable results confirmed by high coherency ( $\geq 0.5)$ are indicated by solid circles, and unreliable ones (coherency $<0.5$ ) are shown by open circles. (c) Result of fitting inside each sliding window. The observed and synthetic profiles are shown by solid and dashed lines, respectively. The synthetic anomalies are multiplied by the estimated magnetization (the ratio). Results with high coherency $(\geq 0.5)$ are distinguished by an open segment number on a black circle. 
(a) $1 \ldots{ }^{5} \ldots{ }^{10} \ldots .^{15} \ldots{ }^{20} \ldots{ }^{25} \ldots{ }^{30} \ldots{ }^{35} \ldots{ }^{40} \ldots .^{45} \ldots{ }^{50} \ldots .^{55} \ldots{ }^{60}$.

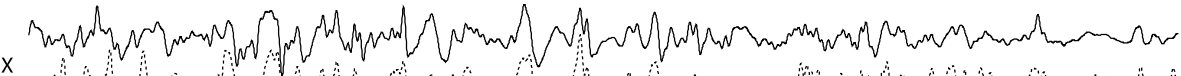

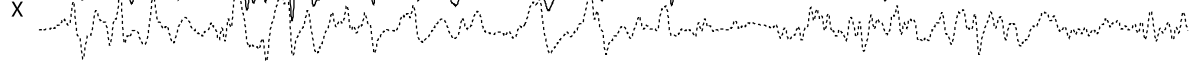


Z A

$\longmapsto$ sliding window width (256m) observed [2000 nT synthetic $200 \mathrm{nT}$

(b)
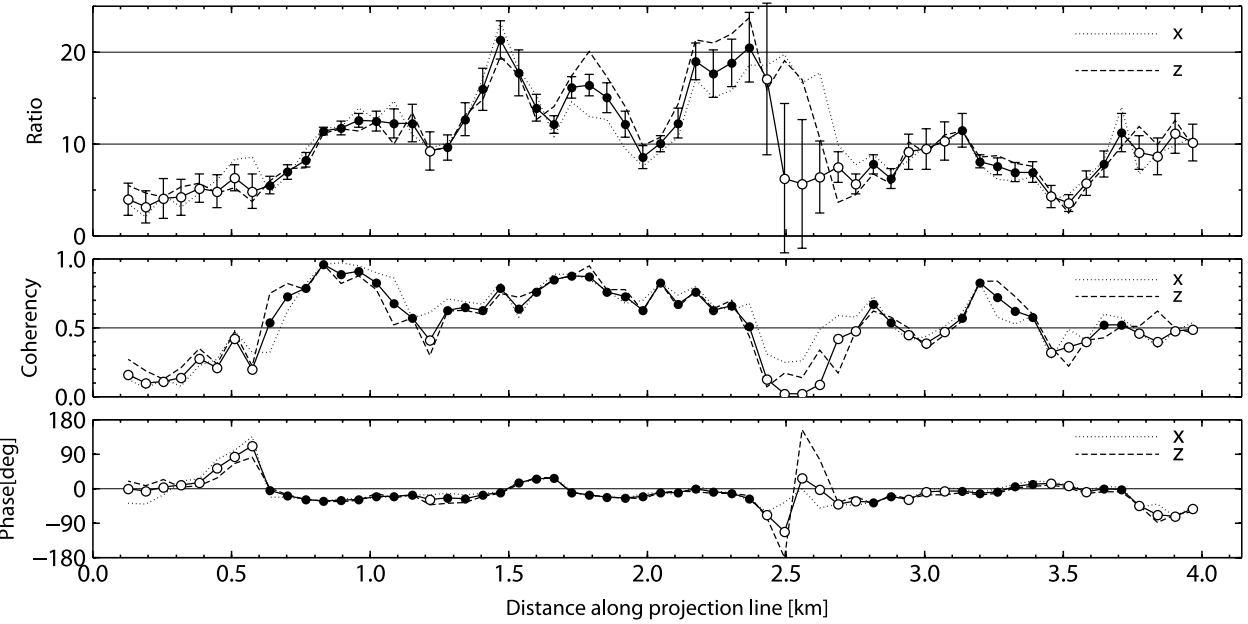

(c)



Figure 6 
[18] The amplitude of the magnetic anomaly assuming an uniform magnetization for the source is proportional to the intensity of magnetization. Therefore the ratio of the observed magnetic anomaly to the synthetic one computed for a $1 \mathrm{~A} / \mathrm{m}$ magnetization intensity represents the real magnetization intensity of the seafloor. For a quantitative estimation of this ratio we utilized the technique of linear transfer function in the Fourier domain, which has been used in many gravity studies to estimate a ratio of gravity to elevation as a function of wave number [McKenzie and Bowin, 1976; Watts, 1978].

[19] The magnetization was estimated on a $256 \mathrm{~m}$ wide sliding window each $64 \mathrm{~m}$ along a profile; each of the example profiles $\sim 4.2 \mathrm{~km}$ long (Figure $6 \mathrm{a}$ ) gives 61 overlapping small profiles, or "segments" (the center of each segment is indicated by dots on the top of Figure 6a). On each set of the segments of synthetic and observed profiles, their Fourier transforms are first used to obtain the power and cross spectrums to avoid the noise effect [McKenzie and Bowin, 1976]. The spectrums are then averaged over the wavelength between 37 and $256 \mathrm{~m}$ to obtain a ratio of observed to synthetic anomalies (i.e., an estimate of the magnetization intensity) together with its error, and a coherency and a phase (estimates on the similarity between the synthetic and observed profiles). Both sets of segments for the horizontal $(\mathrm{X})$ and vertical $(\mathrm{Z})$ components, providing individual results as well (shown by dotted or dashed lines in Figure $6 \mathrm{~b}$ ), are used together in the process of averaging of the spectrums to obtain the final result (shown by circles with solid lines in Figure 6b). Figure 6c shows the comparison between synthetic and observed profiles inside each sliding window. The synthetic anomalies are multiplied by the estimated magnetization. It was practically decided that estimations with a coherency higher than or equal to 0.5 were regarded as reliable; they are distinguished by open segment numbers on black circles in Figure 6c, and by solid circles in Figure $6 \mathrm{~b}$.

[20] In Figure $6 \mathrm{~b}$ the results from $\mathrm{X}$ and $\mathrm{Z}$ components are not exactly identical, but show similar variations indicating the validity of the two-dimensional assumption. The phase, that is expected to be 0 or $180^{\circ}$ (in cases of normally or reversely magnetized crust, respectively), is close to $0^{\circ}$ in most part; it considerably deviates from $0^{\circ}$ near $\mathrm{x}=\sim 0.5$, $\sim 2.5$ and beyond $\mathrm{x}=\sim 3.7$, but such phase values are all accompanied by coherencies lower than 0.5 and regarded as unreliable estimates.

[21] It is worth noting that the magnetization intensity estimated by this method represents "true" or "absolute" intensity, i.e., it is independent of any assumption on the thickness of the source layer and therefore no need to deal with the annihilator, unlike the equivalent magnetization obtained from the inversion of sea-surface or deep-tow magnetic anomaly data [Parker and Huestis, 1974; Macdonald et al., 1980; Hussenoeder et al., 1995], as long as the magnetic layer is expected thicker than $\sim 100 \mathrm{~m}$ (see previous discussion). In this sense it would compare to the NRM measurement of sample rocks, laterally averaged over the sliding window length $(256 \mathrm{~m})$ used for the estimation.

\subsection{Inversion Analysis}

[22] In contrast to the short-wavelength component which reflects the magnetic structure of the shallow part of crust, the long-wavelength component of the deep-sea magnetic anomalies gives information on the average structure of the magnetic layer over greater depth. We applied the magnetic inversion to five dives that are expected from the sea-surface magnetics to cross the magnetic polarity boundaries. In this section we describe the application of the deep-sea magnetic data inversion to dive 05 , possibly crossing the eastern $\mathrm{B} / \mathrm{M}$ boundary, as an example. Results and interpretations of other dives will be presented in section 6 .

[23] The magnetic inversion technique using data on a level plane has been well established by Parker and Huestis [1974]. There are several ways to deal with data acquired on an uneven track. One is that data are first reduced to a level plane [Guspi, 1987; Pilkington and Urquhart, 1990] and then used for the inversion. These reduction methods, however, accompany a loss of spatial resolution due to a high-cut filter required to ensure the convergence of calculation. Actually, as much as a $\sim 1 \mathrm{~km}$ or longer wavelength high-cut filter is needed to apply the reduction method of Guspi [1987] to our data, due to large amplitude of depth of the observation paths. Filtering to such a long wavelength suppresses a substantial part of the signals in our data profiles. Another method is what is called "direct inversion" [Hussenoeder et al., 1995], where the reduction procedure is bypassed and data are directly inverted to avoid a loss of resolution. In this method, such an equivalent geometry that maintains flying height variations and exhibits a level observation plane is considered to apply the inversion method of Parker and Huestis [1974]. To correct the error caused by switching geometry, Hussenoeder et al. [1995] introduced a correction factor calculated from the evaluated error for an assumed uniform magnetization. We used the same idea of the equivalent geometry as Hussenoeder et al. [1995], but for this correction we adopted an iterative procedure as follows:

[24] 1. Assuming a substitute geometry of a level observation plane and a topography that maintains flying height (altitude) [Hussenoeder et al., 1995], invert observed magnetic anomalies to magnetization distribution by using the method of Parker and Huestis [1974].

[25] 2. Using this inversion solution and the real geometry, calculate magnetic anomalies along the dive path.

[26] 3. Using the substitute geometry of step 1 , solve such a magnetization distribution that corrects the difference between step 2 and the observed anomalies by the method of Parker and Huestis [1974], and add the solution to step 1 to obtain the next solution.

[27] 4. Repeat steps 2 and 3 until the magnetization solution converges.

[28] A two-dimensional geometry in the axial direction $\left(\mathrm{N} 12^{\circ} \mathrm{E}\right)$, a $500 \mathrm{~m}$ thick magnetic layer, and a direction of magnetization parallel to the geocentric axial dipole field were assumed. In step 2, we utilized the same polygonal approach of Talwani and Heirtzler [1964] as used in the forward modeling analysis, but considering contribution from vertical sides within the magnetic layer as well to represent the horizontally varying magnetization. The annihilator, a magnetization distribution that yields no magnetic anomalies [Parker and Huestis, 1974], can be solved by the same procedure. Concerning our data, the idea of correction factor presented by Hussenoeder et al. [1995] worked insufficiently to obtain such a magnetization distribution that could reproduce the observed anomalies along dive paths. 


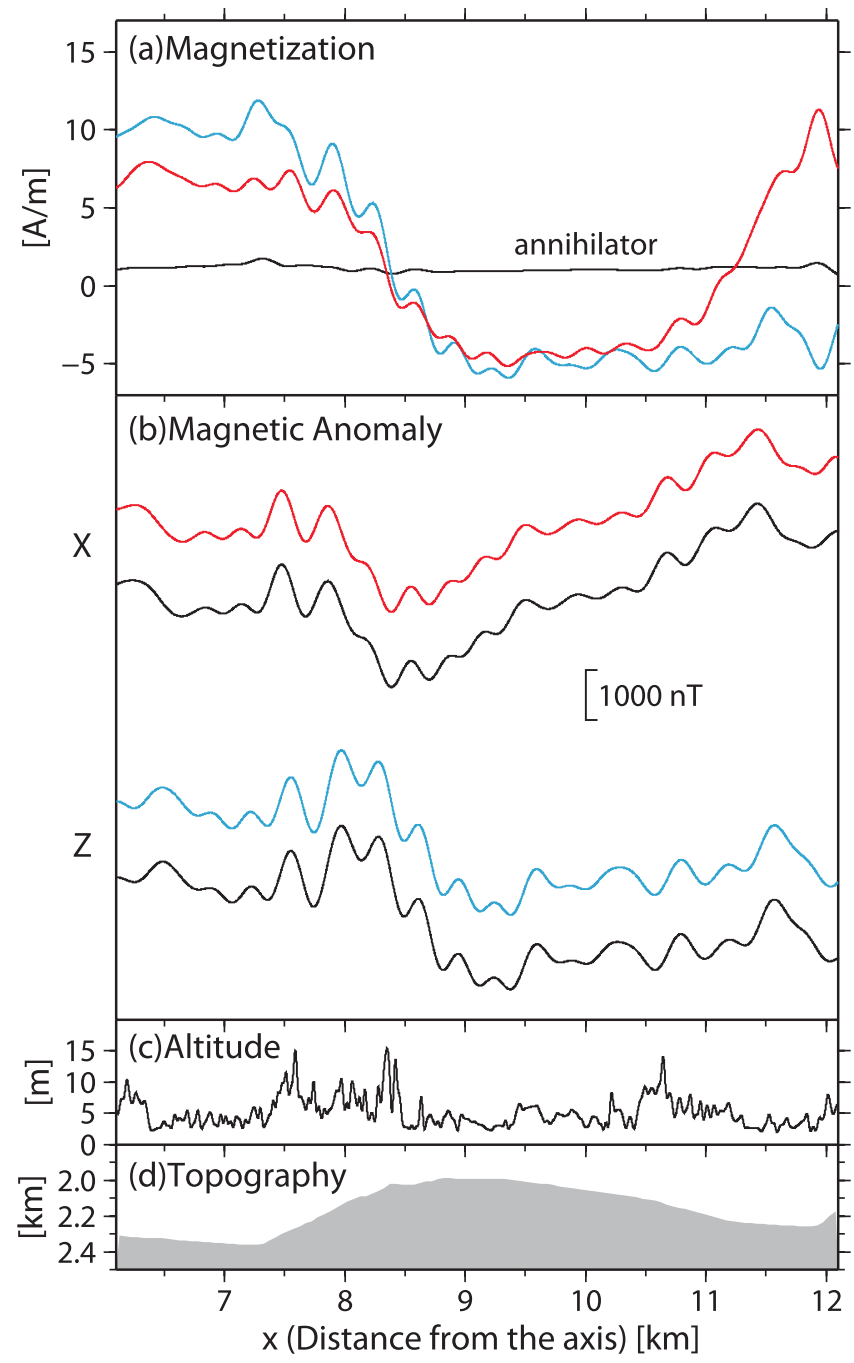

Figure 7. An example of the application of two-dimensional magnetic inversion to the deep-sea magnetic data (dive 05). (a) Obtained magnetization distributions derived from the horizontal $(\mathrm{X})$ and vertical $(\mathrm{Z})$ components of anomalies, shown by red and blue lines, respectively. The annihilator is shown by a black line. Ten iterative procedures to correct the error due to switching geometry (see text for details) brought enough convergence of the magnetization solution. A high-cut filter, a cosine curve of 1.0 at the wavelength of $300 \mathrm{~m}$ and 0.0 at $250 \mathrm{~m}$, is used in the inversion calculation. (b) Comparison between the observed anomalies (black lines) and the synthetic ones (red or blue lines) reproduced from the magnetization distribution (Figure 7a) and the real geometry of topography and observation path. (c) Altitude. (d) Topography.

It may be due to relatively large contribution of the nonlinear effect of the magnetization distribution and topography to the magnetic anomaly, that is not included in the correction.

[29] Figure 7 shows an example (dive 05) of the obtained magnetization distribution and the comparison between the observed anomalies and reproduced ones calculated from the obtained solution and the real geometry. The horizontal axis in Figure 7 represents the distance from the axis, as the data are projected onto a line in the spreading direction. The horizontal (X) and vertical (Z) components of anomalies are individually used for calculation to yield the respective solutions (red and blue lines in Figure 7a), that successfully reproduce the observed anomalies (Figure 7b). The inversion method of Parker and Huestis [1974] used for total field anomalies can be equally adapted to these component anomalies with a slight modification, because the total field anomaly is actually approximated by a component anomaly in the direction of the ambient field in their method. Despite discrepancy between the solutions calculated from the $\mathrm{X}$ and $\mathrm{Z}$ components that would be caused by deviation from the assumption of two-dimensionality, they show a consistent decrease in magnetization at $x=7.5 \sim 9.0$, representing the Brunhes-Matuyama magnetic boundary.

\section{Results and Evaluation of Forward Modeling Analysis}

\subsection{Results}

[30] The results of forward modeling and magnetization estimation for all 19 dives are shown in Figure 8, together with the bathymetric profiles and the NRM values of basalt samples (the NRM measurements of the samples are described in section 5.4). If the dive track changes its course significantly (the case of dives 06, 09, 11, 14, 18, 19 and 20) it is divided into several tracks with almost constant course and each track is projected onto a straight line separately. As for dives 05,12 and 17 , the width of sliding window was doubled $(512 \mathrm{~m})$ for adjustment to the wavelength of anomalies associated with the local topography, and the interval of magnetization estimation was doubled accordingly $(126 \mathrm{~m})$. The polarity of the magnetization is regarded positive (normal) if the phase is between $-90^{\circ}$ and $90^{\circ}$ and negative (reversed) otherwise. Except for the dives far away from the axis (dives 05, 07, 08 and 09) most of the estimates with high coherency are positive, representing the Brunhes normal epoch. The estimated magnetizations with high coherency range from 0 to $35 \mathrm{~A} / \mathrm{m}$, and more than $90 \%$ of them are between 0 and $20 \mathrm{~A} / \mathrm{m}$.

\subsection{Further Inspection}

[31] Although a high coherency ensures a good correlation between the predicted and observed anomalies, it is impossible to rule out local changes in the magnetization intensity, either due to a disturbance in magnetization direction resulting from faulting, block rotation or false topography as a result of sediment burial. These would result in anomalies resembling the predicted ones and lead to incorrect estimations, as a consequence of the intrinsic nonuniqueness of the potential field problem. However, we consider the estimated magnetization valid if the predicted and observed anomalies have distinctive shapes produced by the local topography, and/or that they resemble each other over some distance resulting in consecutive high coherencies. Many of these convincing estimates are obtained for dives close to the spreading axis, for example, parts of dives $20,18,02,16$ and 13. On the other hand, less reliable estimates are obtained off-axis. In particular, the estimates accompanying high coherency are sparse on the gradual slopes facing away from the axis (e.g., parts of the dives 09, 08, 05, 07 and 04), where topography is smooth and the magnetic anomalies are generally small in amplitude. After a close inspection some of the high coherency picks among generally low coherencies were 

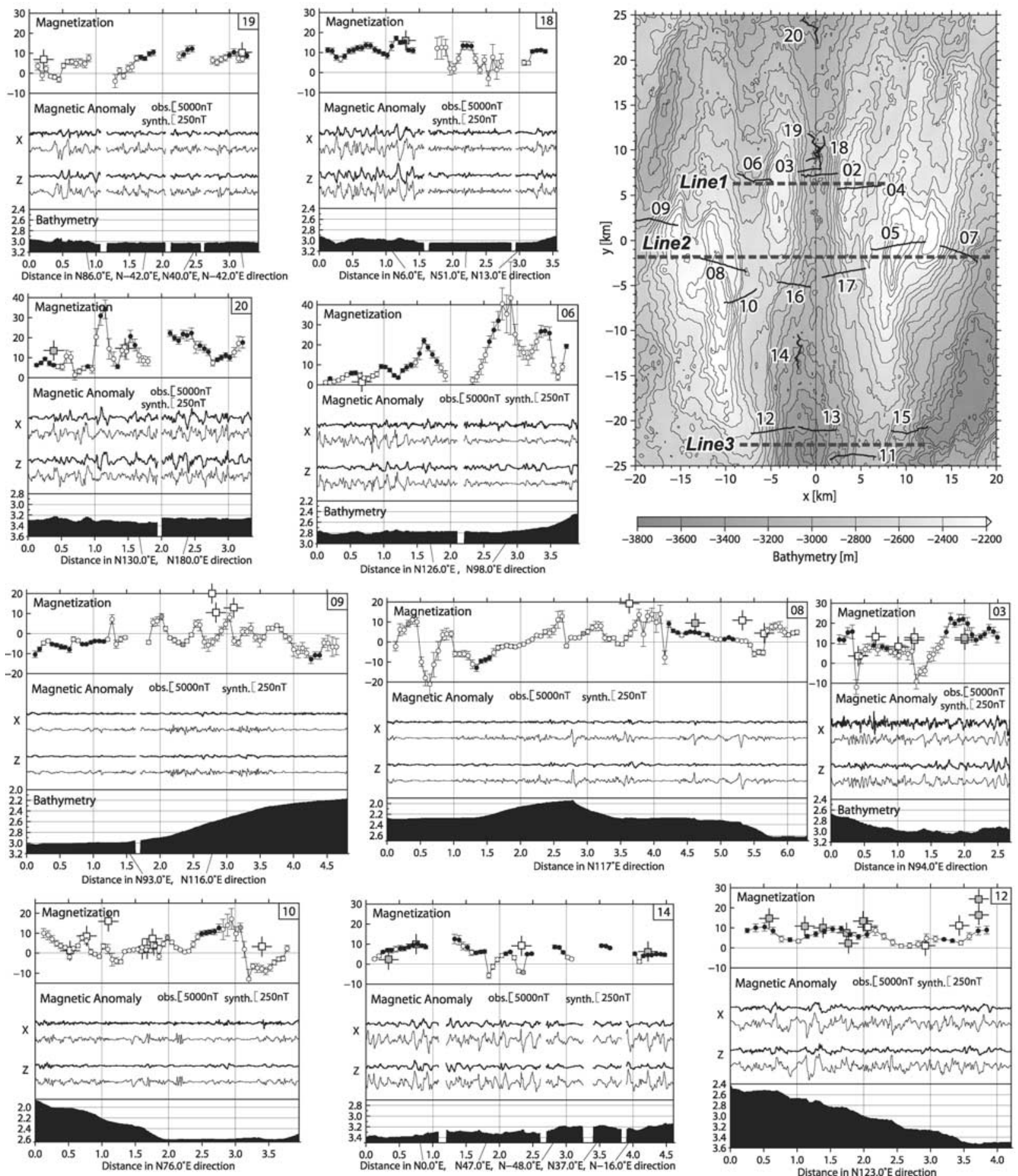

Figure 8. Results of all 19 dives (numbered from 02 to 20). Three bold broken lines in the index map (indicated as Lines 1,2, and 3) are the projection lines of the across-axis profiles shown in Figure 11. Each graph contains (from bottom to top) bathymetry (shades), observed and calculated anomalies (thin and bold lines, respectively) at different scales, and estimated magnetization intensity (solid/light-shaded/open circles with error bars). The reliable estimations confirmed by high coherency $(\geq 0.5)$ are indicated by solid circles, and less reliable ones (coherency $<0.5$ ) are shown by open circles. Estimates regarded as not convincing by further inspection in spite of high coherency are shown by light-shaded circles (see text for details). The locations and NRM values of basalt samples are plotted together with open or shaded squares with crosses. The NRM values indicated by shaded squares are selected to be compared with magnetizations estimated from anomalies in Figure 9 (see text for detail). The direction of projection line is indicated along the horizontal axis. In the case where the dive track has considerable change of course (which is the case for dives $06,09,11,14,18,19$, and 20), it is divided into several tracks, each of which has an almost constant course, and each track is projected onto a straight line separately. 

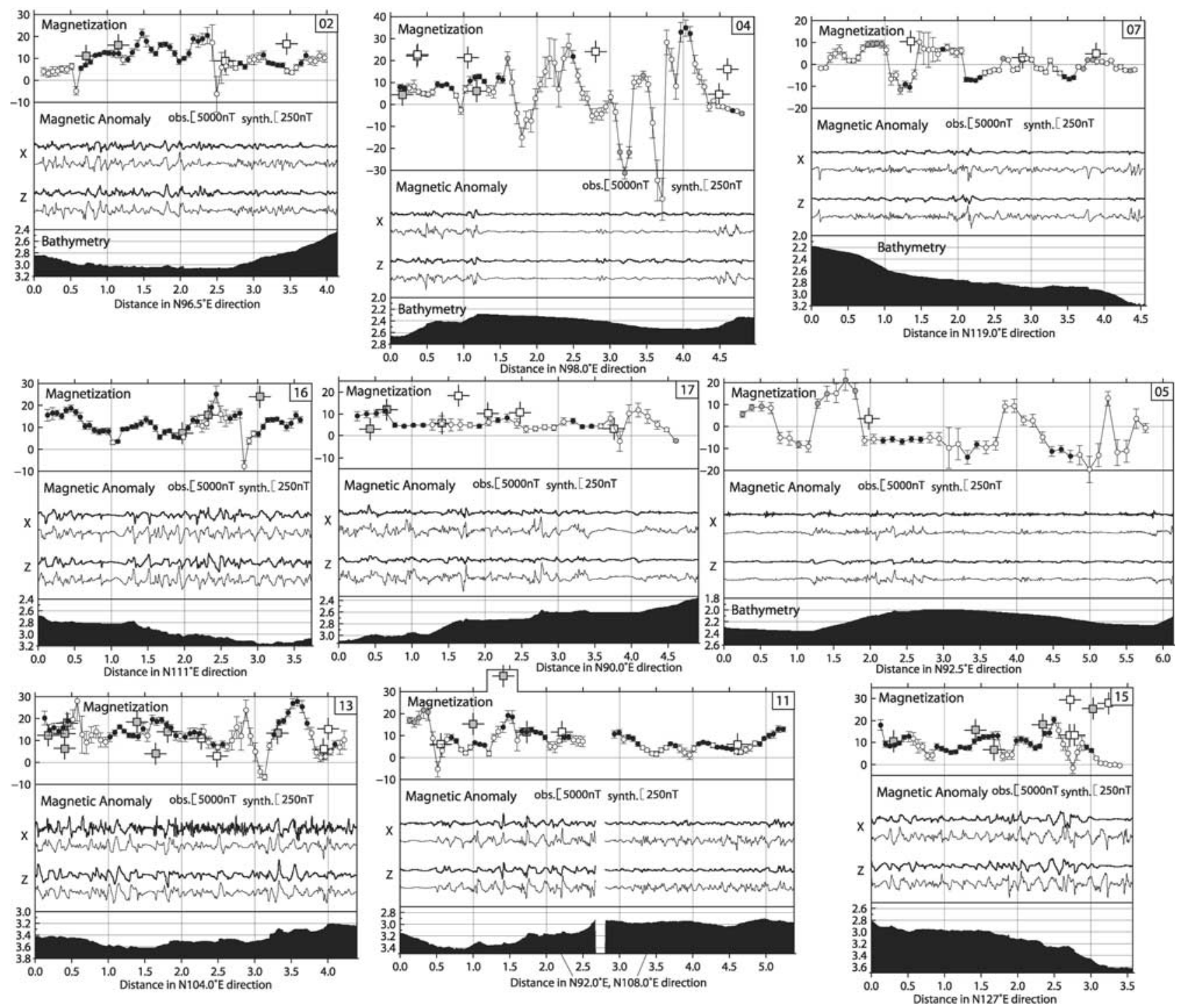

Figure 8. (continued)

downgraded to unreliable (indicated by light-shaded circles in Figure 8) because they have too simple a shape to be confirmed as topography-caused (a single arch, for example) and/or because the neighboring estimates are too different (as our method should not work effectively if such shortwavelength variation of magnetization exists in the first place). Among the 464 estimates associated with high coherency, 37 are regarded as unreliable by this close inspection procedure.

\subsection{Effects of the Sediments}

[32] As expected, the direct observations on board Nautile suggest that sedimentary cover thickens with age away from the axis; fresh basalt outcrops are progressively covered with sediment and the low topography is buried until the volcanic morphology disappears. On most off-axis dives (dives 09 and 07), only the top of volcanic cones and the steepest escarpments had underlying basalt outcropping on the seafloor. Because no seismic data are available to evaluate the sedimentary thickness in such areas, the application of our method to determine the absolute magnetization is not straightforward. Nevertheless, we applied the method using the observed topography, assuming that the requirement of high coherency would exclude most of the wrong estimations derived from inaccurate predictions of the magnetic anomaly due to the sedimentary cover. We obtained many unreliable estimates with low coherency for the off-axis dives. Despite this shortcoming, the method also provided a significant number of reliable determinations, probably because the off-axis dives generally ran perpendicular to seafloor structures and the two-dimensional assumption is valid to a first order. Dive 15 displays a series of consecutive high coherencies although it is one of the furthest off-axis dives and has significant sediment cover. If we consider a level dive path for simplicity, a uniform sediment cover should result in an underestimate of the magnetization intensity as the synthetic anomalies are computed for a topography closer to the observation point than the actual top of the magnetic source. Sediments not only bury topography but also raise the topography level thereby moving the measurement level further from the basement source rocks: the former results in overestimating the magnetization intensity and the latter to underestimates. This simple discussion shows that the sediment cover may 
lead to overestimates or underestimates without significant decrease in coherency. We evaluated these effects: a sediment thickness of $2 \mathrm{~m}$ and an altitude of the vehicle of $10 \mathrm{~m}$ results in underestimation or overestimation by factors of $0.9-1.2$.

\subsection{Comparison With NRM Measured on Basaltic Rock Samples}

[33] About 200 samples were collected during the 19 Nautile dives with 127 suitable for subsampling by cores, our preferred sampling method for NRM determination. Measurements were carried out at Université de Montpellier for 26 samples from the segment center transect (near $\mathrm{y}=5$, Figure 1b) and for 40 samples from the intermediate transect (near $\mathrm{y}=-2$ ) [Ravilly et al., 2001] and at Ecole Normale Supérieure de Paris for samples from the transect at the southern segment end (near $y=-22$ ) and the complementary dives along the ridge axis. NRM intensity was measured using a JR5 spinner magnetometer (specified accuracy of $1 \%$ ). In Montpellier measurements were performed on cylindrical specimens, $1 \mathrm{~cm}$ long and $2.5 \mathrm{~cm}$ in diameter, in a nonmagnetic room. In Paris NRM was measured on cylindrical specimens, $1.5 \mathrm{~cm}$ long and $1.2 \mathrm{~cm}$ in diameter, after storage for 2 days in a low field to minimize the viscous magnetization.

[34] We can compare our magnetization estimates from the submersible profiles with the NRM measured on the samples collected by Nautile along the same profile. The values of estimated magnetization and coherency at the sampling sites were evaluated by linear interpolation of these values, and the comparison was made only if the estimation from anomalies is confirmed as reliable by high $(\geq 0.5)$ coherency. Beyond the eliminations due to low coherency, comparisons cannot be made at a significant number of sampling sites because they are located at the beginning or at the end of each dive, out of the range of the magnetic measurements. The 41 remaining NRM values (indicated as shaded squares with crosses in Figure 8) are compared with the results from anomalies in Figure 9. The difference in value almost follows a normal distribution centered on zero and is lower than $5 \mathrm{~A} / \mathrm{m}$ for $54 \%$ (22 data) of the available data. Although both results show similar range of magnetization intensity, a linear regression analysis gave the coefficient of determination $\mathrm{R}^{2}<0.01$, meaning no correlation between them. NRM measurements on small samples may not properly represent the average magnetization of the seafloor, as large variations have been observed even at the scale of single pillow lava [e.g., Zhou et al., 2000; Carlut and Kent, 2002]. Although we have attempted to make our NRM measurements at some distance from the glassy rim to avoid the strong variations observed in this part of the pillow lava, the available sample collection did not allow us to drill the mini cores at a constant distance from this glassy rim. Moreover, although we have tried to use the less altered parts of the samples, they present quite a range in the amount of alteration, with probable consequences on their NRM. Conversely, the magnetization determined from the anomalies averages the rock NRM over a few tens to hundreds meters along the submersible path and on a few tens meters both laterally and vertically. Although the good coherency values obtained between the observed and synthetic anomalies support some uniformity in the average seafloor magnetization at these scales, this average magnetization would hide variations at the scale of individual



(b)

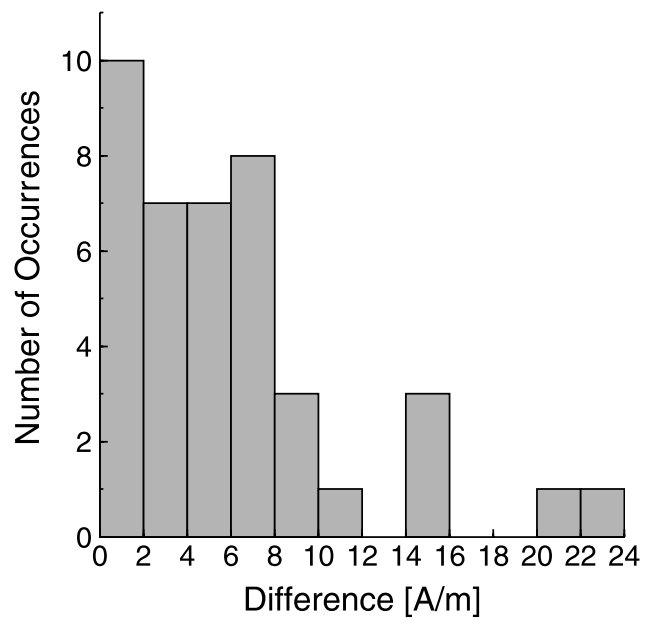

Figure 9. (a) Comparison of the NRM measured on samples (vertical axis) and the magnetization from anomalies (horizontal axis), made on 41 samples whose locations correspond to a reliable estimation of the seafloor magnetization. Data with difference lower than $5 \mathrm{~A} / \mathrm{m}$ (those falling between the upper and lower lines) is 54\% (22 data). (b) Histogram of the difference.

pillow lava or within the lava pile. Considering these limitations, the comparison between the magnetization derived from anomalies and measured on samples is encouraging and reinforces our confidence in the methodology developed to determine the absolute magnetization of the seafloor from the near-bottom magnetic anomalies.

\section{Discussion}

\subsection{Magnetization Variation Along the Axis}

[35] We compiled the results of the eight dive surveys conducted in the axial zone at different places in the segment to investigate the along-axis variation of the axial magneti- 


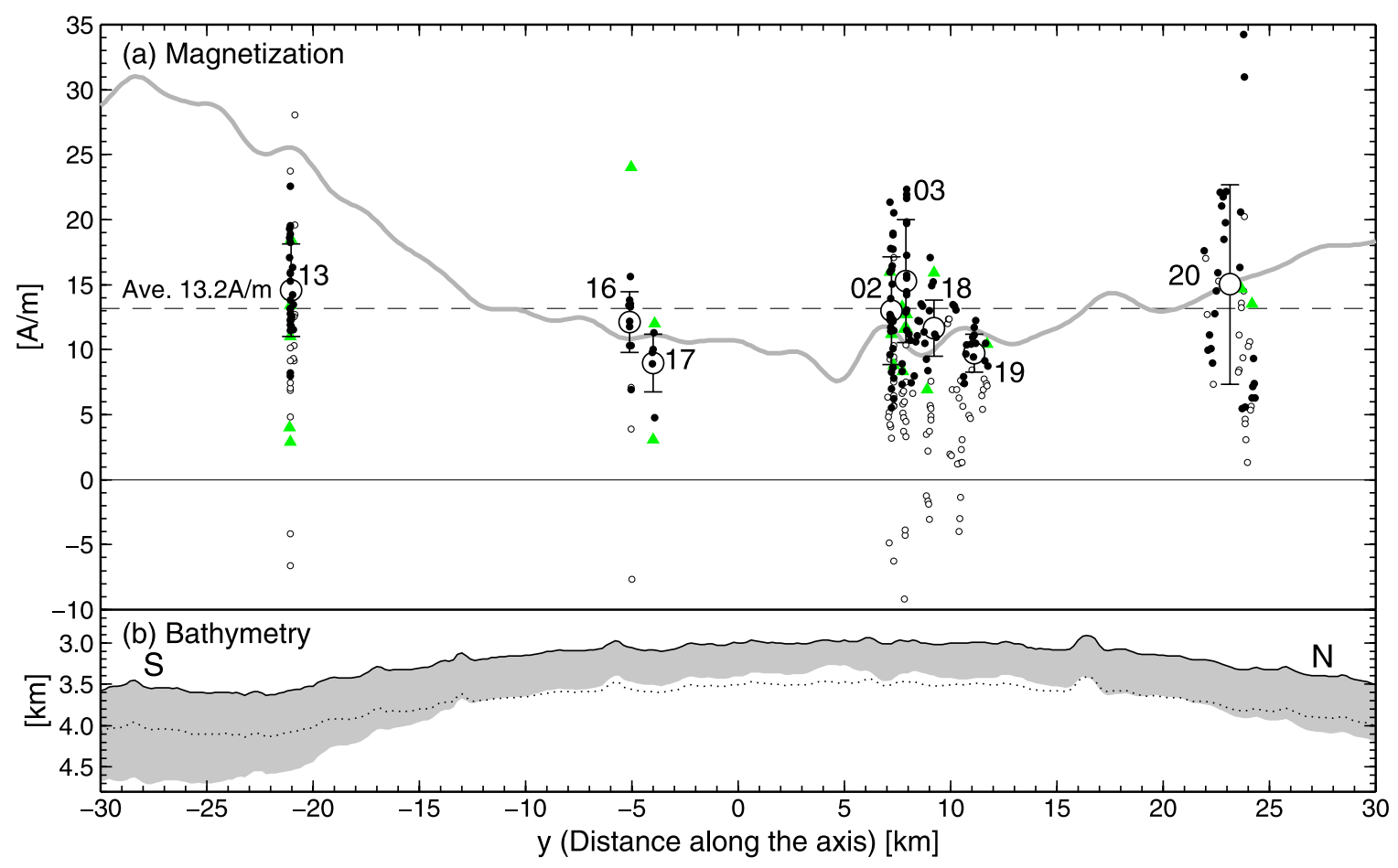

Figure 10. (a) Compilation of magnetization in the axial zone (within $1.5 \mathrm{~km}$ of the axis). Magnetizations from the deep-sea anomalies are shown by small solid/open circles (see the caption of Figure 8). Large open circles with error bars represent the average of reliable estimates for each dive. NRM values of basaltic samples are shown by green triangles. Cross section of the sea-surface inversion result is shown by a bold gray line (extracted from Figure 1d along $\mathrm{x}=0$ ). (b) Along-axis bathymetric cross section. Dotted line represents the magnetic layer of a constant thickness $(500 \mathrm{~m})$ assumed in the sea-surface inversion, while gray shade shows the comparable magnetic layer of a constant magnetization $(13.2 \mathrm{~A} / \mathrm{m}$; see text for details).

zation. The magnetization values obtained within the area between $\mathrm{x}=-1.5$ and $\mathrm{x}=1.5$ (corresponding to the inner floor width near the segment center) are selected and plotted in Figure 10a. The average of reliable estimations for each dive ranges from 8.9 (dive 17) to 15.3 (dive 03 ) $\mathrm{A} / \mathrm{m}$, and the average value for all reliable data is $13.2 \mathrm{~A} / \mathrm{m}$.

[36] Magnetization intensity shows no systematic variation along axis other than the dispersion within each dive. Rock sample NRM also shows no variation along axis. On the other hand, the equivalent magnetization derived from the sea-surface magnetic anomalies shows a considerable increase from the center to both the ends of the segment: a relative low $(\sim 10 \mathrm{~A} / \mathrm{m})$ at the segment center, a very strong high $(\sim 30 \mathrm{~A} / \mathrm{m})$ at the southern segment end and a weaker high $(\sim 18 \mathrm{~A} / \mathrm{m})$ at the northern segment end. The magnetization values of the northernmost dive 20 seem to be scattered to higher values, and the average values for both the end dives 13 and 20 are slightly higher compared with the other dives near the segment center except for dive 03 . However, the difference is much more moderate than that of the equivalent magnetization.

[37] This result contradicts previous studies that ascribe the high amplitude of sea-surface magnetic anomalies at segment ends to along-axis variations of geochemical and magnetic properties of basaltic rocks [e.g., Sempere, 1991; Weiland et al., 1996; Gee and Kent, 1997; Horen and Fleutelot, 1998]. In support to our observation of a rather constant magnetiza- tion along the axis, the petrology of pillow lava glasses collected during the survey is quite uniform, with a magnesium oxide content ranging between 6.8 and $8.9 \mathrm{wt} \%$, a total iron oxide content between 7.8 and $10.4 \mathrm{wt} \%$, and a titanium oxide content between 1.0 and $1.9 \%$ (G. Ceuleneer, personal communication, 2001; G. Ceuleneer, manuscript in preparation, 2009). Scattering of about $2 \mathrm{wt} \%$ affects these measurements and partially hides a trend for slightly lower $\mathrm{MgO}$, higher $\mathrm{FeO}$ and higher $\mathrm{TiO}_{2}$ content toward segment ends. A much clearer petrological trend is observed on the MAR $24^{\circ} \mathrm{N}$ segment immediately north of Kane Fracture Zone, with $\mathrm{MgO}$ content of about $8.5 \mathrm{wt} \%$ at the segment center and $6.5 \mathrm{wt} \%$ at the segment ends [Lawson et al., 1996]. The similar range of petrological variations on both the MAR $24^{\circ} \mathrm{N}$ and MAR $21^{\circ} 40^{\prime} \mathrm{N}$ segments as well as the similar wavelength of these variations on the fully sampled MAR $24^{\circ} \mathrm{N}$ segment [Lawson et al., 1996] make unlikely the possibility that our sampling missed a similar zone of highly evolved, iron-rich basalt, located south of dive 13, within the $20 \mathrm{~km}$ separating this dive from the southern segment tip marked by the nodal basin at $21^{\circ} 20^{\prime} \mathrm{N}$ [Gente et al., 1995].

[38] Assuming that our result of a high equivalent magnetization at segment ends arises from a thicker magnetized layer rather than a higher magnetization of the basalt, we roughly estimate how much thicker the magnetic layer should be at segment ends by simply converting the varying equivalent magnetization computed for a constant magnetic layer 
thickness of $500 \mathrm{~m}$ onto a varying magnetic layer thickness assuming a constant magnetization intensity of $13.2 \mathrm{~A} / \mathrm{m}$, keeping the vertically integrated amount of magnetization unchanged. This simple conversion tends to slightly underestimate the thickness required at the segment ends because the deeper part of the magnetic layer has a lower contribution at the sea surface. With this caveat the magnetic layer thickness is estimated from about $400 \mathrm{~m}$ at the segment center to more than $1100 \mathrm{~m}$ at its southern end (a gray shade in Figure 10b).

[39] An immediate and simple explanation for such thickness variations of the magnetic layer would be depth variations of the Curie isotherm in the basaltic layer $\left(100^{\circ} \mathrm{C}-150^{\circ} \mathrm{C}\right.$ for unaltered titanomagnetite). As a result of three-dimensional, focused mantle upwelling at slow spreading centers [e.g., Lin and Phipps Morgan, 1992; Gac et al., 2003], the isotherms are shallower at segment centers than near segment ends. Three-dimensional thermal and magnetic modeling of a slow spreading ridge segment shows, however, that such an explanation is not valid in explaining the amplitude variations of axial magnetic anomalies, as "Curie isotherms of extrusive and intrusive basalt are clearly deeper than the base of their respective layer and do not affect the shape of the magnetized basaltic layer" [Gac et al., 2003]. Variations in Curie isotherm depth can only locally affect the shape of the anomaly, near a zone of active dike injection or hydrothermal fluid vent [Shah et al., 2003; Tivey et al., 1993; Tivey and Johnson, 2002].

[40] A problem with the hypothesis of a basaltic layer thicker at segment ends than at segment center is that it contradicts the available geological model, which suggests a thick crust at segment center and a thinner crust toward segment ends. The model is consistently supported by seismic studies [Tolstoy et al., 1993; Detrick et al., 1993; Hooft et al., 2000; Canales et al., 2000], gravity studies [Lin et al., 1990; Detrick et al., 1995; Pariso et al., 1996; Maia and Gente, 1998] and the direct observation and sampling of deep crustal and mantle rocks at segment ends [Juteau et al., 1990; Cannat, 1993; Cannat et al., 1995; Gràcia et al., 1997]. The MAR $21^{\circ} 40^{\prime} \mathrm{N}$ segment exhibits the characteristics of slow spreading ridge segments: it shows a pronounced circular "bull's-eye" pattern of low mantle Bouguer anomalies [Maia and Gente, 1998; Thibaud et al., 1998], and ultramafic and gabbroic rocks were sampled in the discontinuity bounding the northern end of the segment [Cannat et al., 1995]. From these observations, it is quite clear that the MAR $21^{\circ} 40^{\prime} \mathrm{N}$ segment also presents a substantially thinner magmatic crust at segment ends than at segment center, and therefore that a thicker basaltic layer at segment ends is not a viable hypothesis.

[41] An alternative magnetic source at segment ends could be serpentinized peridotite [Pariso et al., 1996; Tivey and Tucholke, 1998]. The preferential serpentinization at segment ends would indirectly result from the low magma supply, through both a thin magmatic crust and the extensive fracture, and therefore to the easy penetration of seawater to mantle rocks and their pervasive alteration to serpentinite. Serpentinized peridotite can bear a strong NRM and a high susceptibility, sufficient for the contribution to the ocean magnetic anomalies [Harrison, 1987]. For instance, 30 samples of serpentinized peridotites recovered from Ocean Drilling Program hole $670 \mathrm{~A}$, located in the median valley of the MAR south of Kane Fracture Zone, provided a mean NRM of $2.5 \mathrm{~A} / \mathrm{m}$ and a mean Koenisberger ratio of 1.5 [Hamano et al., 1990]. The analysis of 57 samples of serpentinized peridotite collected at five ODP sites (including hole 670A) gave a mean NRM of $3.5 \mathrm{~A} / \mathrm{m}$ and a mean Koenisberger ratio of about 2 [Nazarova, 1994]. These results suggest that serpentinized peridotites beneath spreading axes could bear a total magnetization intensity of about 4-7 A/m. Conversely, Detrick et al. [1993] demonstrated from a review of seismic data that the North Atlantic fracture zones present an anomalous seismic velocity structure, i.e., a linear velocity increase with depth without any distinct change in the velocity gradient at the inferred boundary between seismic layers 2 and 3. This peculiar seismic structure is interpreted as a thin, intensely fractured and altered basaltic crust overlaying serpentinized peridotite. Canales et al. [2000] found a similar anomalous seismic velocity structure at a nontransform ridge offset near the MAR $34^{\circ} 30^{\prime} \mathrm{N}$, leading them to suggest the presence of a body of partially serpentinized peridotites at least $2.4 \mathrm{~km}$ thick overlain by highly fractured and altered crust. If we assume for simplicity a $400 \mathrm{~m}$ thick extrusive layer with a magnetization intensity of $13.2 \mathrm{~A} / \mathrm{m}$ all along the MAR $21^{\circ} 40^{\prime} \mathrm{N}$ segment, it requires about $2.3 \mathrm{~km}$ thick serpentinized peridotite bodies bearing an average magnetization of $4 \mathrm{~A} / \mathrm{m}$ to account for the along-axis variation of the sea-surface magnetic anomalies. Although serpentinization is a complex process and the magnetization intensity and degree of serpentinization would be different at places [e.g., Toft et al., 1990; Oufi et al., 2002], this model properly explains our magnetic observations and does not quantitatively contradict with the available seismic and petromagnetic evidence.

\subsection{Magnetization Variation Across the Axis}

[42] We compiled results of the fifteen dives that constitute three across-axis sections of the segment to examine the magnetization variation along the spreading direction (Figure 11). The northern section (Line 1: see the index map in Figure 8) composed of dives 06, 03, 02 and 04 (from west to east) crosses the axis at the segment center; the central and longest section (Line 2) composed of dives 09, 08, 10, 16, 17, 05 and 07 is located in an intermediate position between the segment center and the southern end; the southern section (Line 3) composed of dives 12, 13, 11 and 15 crosses the axis about $10 \sim 20 \mathrm{~km}$ north of the southern tip of the segment. From Figure 11 it can be remarked that the most reliable results generally, but not always, correspond to the polarity inferred from the sea-surface inversion. It is also reassuring for our analysis method that some close dives show similar variations to each other: dives 02 and 03 in Line 1 consistently show high magnetizations on the axis flanked by low magnetizations, and dives 08 and 10 in Line 2 show the common magnetization low at $\mathrm{x}=-9.0 \sim-8.5$.

\subsubsection{Locating BM Polarity Boundary}

[43] In the longest section Line 2 (Figure 11b), the deepsea inversion results of three dives (red and blue lines) clearly show the BM transition in the western flank at $\mathrm{x}=-11.5 \sim$ -10.0 (in dive 08) and in the eastern flank at $x=7.5 \sim 9.0$ (in dive 05 ), and probably show the older transition of the Jaramillo event as well at $\mathrm{x}=14.2 \sim 15.2$ (in dive 07 ). Only a limited number of reliable estimates (solid circles) can be obtained around these transitions, but we nevertheless deter- 
[w]

잉융ㅇㅇㅇ

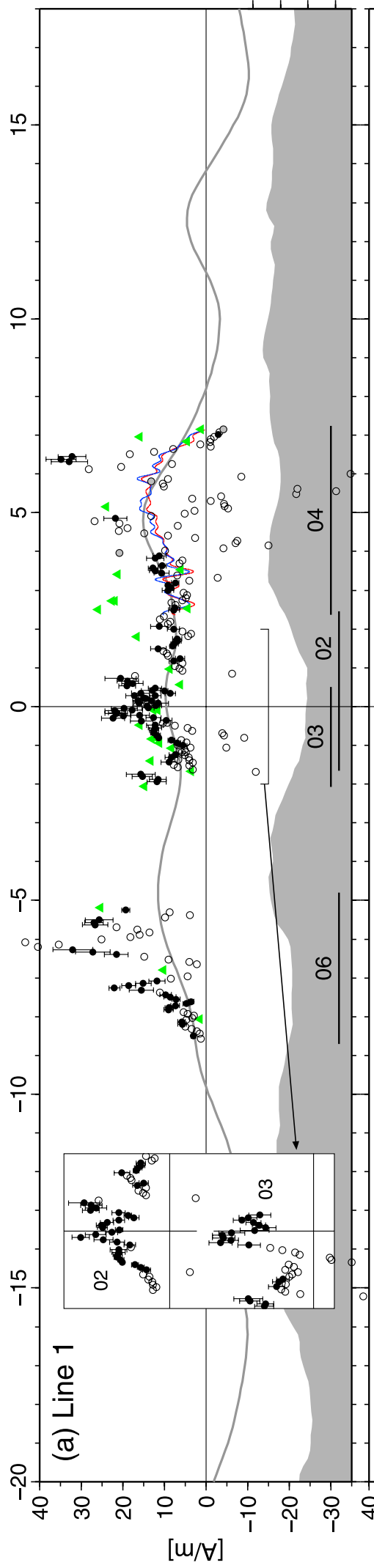

[u]

응융윰 [u]

৪융유

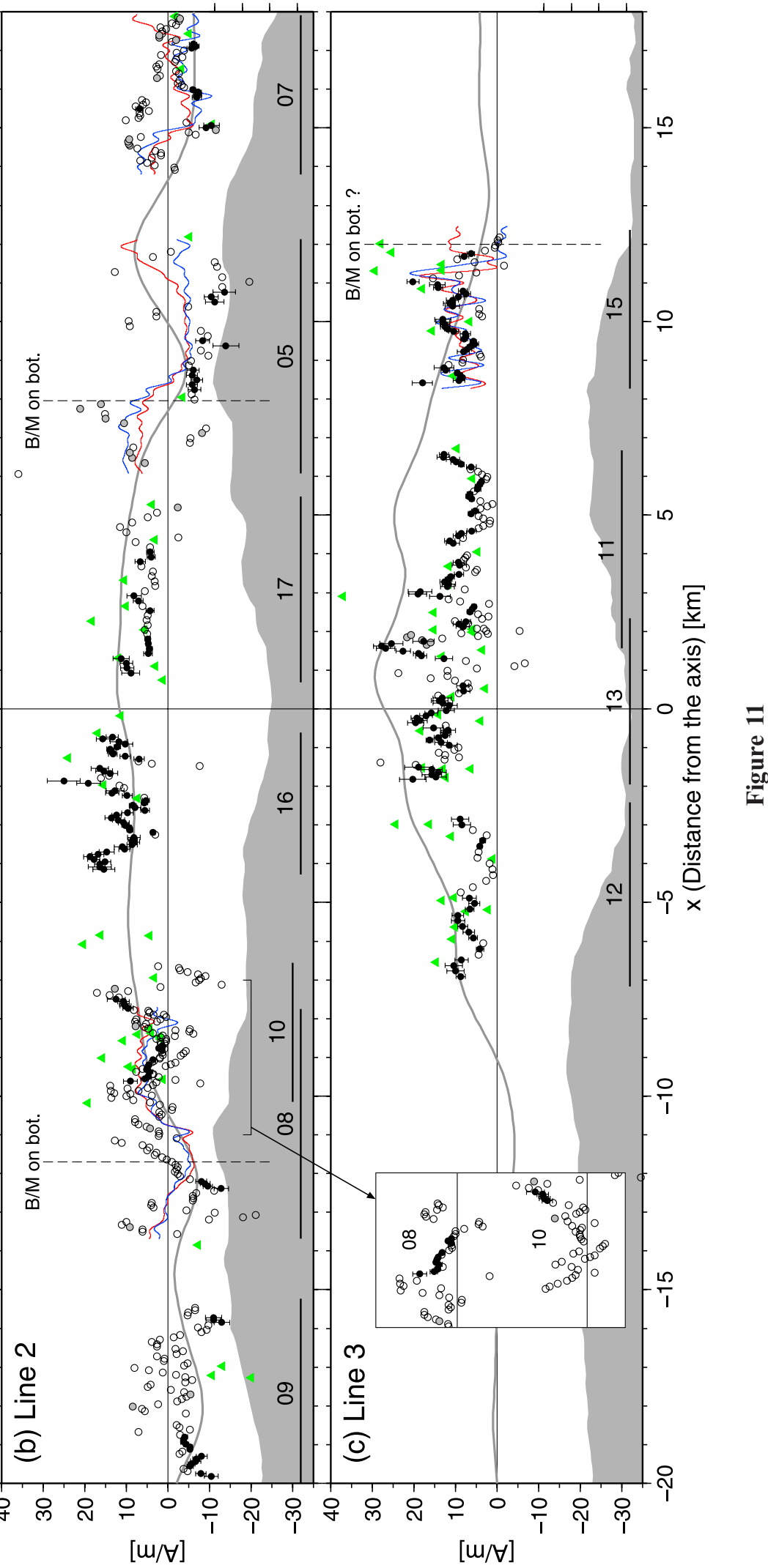


mined the location of the BM boundary on the seafloor approximately at $\mathrm{x}=-11.7$ in the west and at $\mathrm{x}=8.0$ in the east, considering that the dominant polarity appears to change from normal to reversed beyond these locations.

[44] According to the classic model of dipping polarity boundary resulting from the overlapping of lava flows of different polarities, it is expected that the reversal boundary on the seafloor is shifted outward from the boundary calculated from the inversion of deep-sea or sea-surface data [Macdonald et al., 1983]. We could not obtain enough number of reliable magnetization estimates to examine such systematic shift of boundaries. Though dive 07 seems to indicate a lava spillover, dive 05 shows by contraries the on-bottom BM boundary limited to the east by several reliable negatives is displaced ridgeward relative to the transition in the deep-sea inversion. It may be ascribed to complexities in the accretion process at slow spreading ridges compared with that at fast spreading ridges.

[45] In the eastern end of Line 1 (dive 04, in Figure 11a) a series of reversed magnetizations are obtained beyond $\mathrm{x}=$ 6.8 , including one reliable estimate. Both of the deep-sea and sea-surface inversions show rapid decrease in magnetization beyond $\mathrm{x}=\sim 6$, probably indicating the BM transition. It would be then possible to interpret the BM boundary on the seafloor as located at $\mathrm{x}=6.8, \sim 1.2 \mathrm{~km}$ shifted ridgeward relative to that in Line 2 (at $x=8.0$ ). However, we prefer not to consider such shift of the boundary between Lines 1 and 2 neither to regard dive 04 as crossing the BM boundary, because some correspondence is recognized between the variations along Lines 1 and 2; that will be mentioned in section 6.2.4.

[46] In the eastern flank of Line 3, many reliable estimates of the positive magnetization are obtained along dive 15 , showing the extension of normal polarity further beyond the eastern BM boundary of Line $2(x=8.0)$. Widening of the central anomaly from the segment center to the segment ends can also be seen in the sea-surface inversion (Figure 1d), though it may be partly due to the additional deeper source near the segment end (see previous discussion). In the eastern end of dive 15 consecutive reversed or nearly zero intensities are observed beyond $\mathrm{x}=12.0$, though no reliable estimate is obtained there. The deep-sea inversion using the $\mathrm{z}$ component (a blue line) shows a sharp depression near $\mathrm{x}=11.5$ whereas no clear transition is seen in the result of $\mathrm{x}$ component. The BM boundary on the bottom, then, may be located at $\mathrm{x}=12.0$ though there still is a possibility it is further east beyond the reach of dive 15 .

\subsubsection{Variation Within the Brunhes Epoch}

[47] A wide range of magnetization intensity is observed within the Brunhes normal polarity epoch, from a few to a few tens of $\mathrm{A} / \mathrm{m}$. High and low magnetizations seem to compose some across-axis variations rather than be randomly distributed. One of the areas of high magnetization is the axial zone: in Lines 1 and 3 fully crossing the axis, relatively high $(10-20 \mathrm{~A} / \mathrm{m})$ magnetizations are recognized over a width of $\sim 1.5 \mathrm{~km}$ centered at $\mathrm{x}=0$ (Line 1) or $\mathrm{x}=-0.4$ (Line 3), representing the CAMH. As the primary cause of the $\mathrm{CAMH}$, a rapid low-temperature alteration of the basaltic layer has been proposed, with a wide range of the magnetization decay time (e.g., decay to 1/e in $\sim 20 \mathrm{ka}$ [Gee and Kent, 1994], $\sim 100 \mathrm{ka}$ [Johnson and Tivey, 1995]). However, our results also show considerable off-axis variations, that should be attributed to other causes than the magnetization decay with time. Short-wavelength variations of magnetic anomalies within intervals of constant polarity have been widely observed not only in the Brunhes epoch but also in older polarity epochs, i.e., "tiny wiggles" [e.g., Rea and Blakely, 1975; Cande and LaBrecque, 1974; Cande and Kent, 1992; Bouligand et al., 2006]. As for the origin of tiny wiggles, the following explanations have been proposed: (1) local reduction of magnetization caused by alteration and/or tectonic disruption through extensive faulting or hydrothermal activity [Tivey and Johnson, 1987; Hussenoeder et al., 1996; Wooldridge et al., 1990, 1992], (2) varying thickness variation of the magnetized layer [Tivey and Johnson, 1993; Gee and Kent, 1994; Tivey, 1994; Williams et al., 2008], and (3) geomagnetic intensity variation [Cande and Kent, 1992; Gee et al., 1996, 2000; Schouten et al., 1999; Pouliquen et al., 2001; Bouligand et al., 2006]. In our detailed study area we see no clear relationship between the distributions of magnetization low and faulting zone, and we could therefore not ascribe the variation of magnetization within the Brunhes epoch to tectonic demagnetization. Thickness variation of the magnetized layer is out of consideration in this instance because the magnetization intensity obtained using the forward modeling method is the absolute intensity, unrelated to the thickness of source layer. As a possible cause we examine the geomagnetic paleointensity variation.

\subsubsection{Paleointensity-Based Model}

[48] There are several published records of the relative paleointensity derived from deep-sea sediments that span the entire Brunhes period [Kent and Opdyke, 1977; Valet and Meynadier, 1993; Yamazaki et al., 1995; Schneider and Mello, 1996; Channell and Raymo, 2003]. Our result was

Figure 11. Across-axis variation of magnetization along the three lines: (a) Line 1 at the segment center made of dives 06, 03, 02, and 04, (b) Line 2 at an intermediate position made of dives 09, 08, 10, 16, 17, 05, and 07, and (c) Line 3 near the southern segment end made of dives 12, 13, 11, and 15. Extent of each dive is shown by horizontal bar with dive numbers. Magnetizations from the deep-sea anomalies are plotted by solid/light-shaded/open circles (see the caption of Figure 8), and NRM values of basaltic samples are shown by green triangles (in Line 2, those beyond the BM boundaries are plotted as negative). Cross sections of the sea-surface inversion result (bold gray lines) and bathymetry (shades) are extracted from Figures $1 \mathrm{~d}$ and $1 \mathrm{~b}$ along $\mathrm{y}=5,-2$, and -21 for Lines 1,2 , and 3 , respectively. Results of the two-dimensional deep-sea inversion applied to the five dives (04 in Line1, 08, 05, and 07 in Line 2, and 15 in Line 3) are shown by red and blue lines (see the caption of Figure 7): from -5 to 2 times of annihilator were added so as to adjust the mean level to that of the sea-surface inversion. Overlapping dives in Line 1 (dives 02 and 03) and Line 2 (dives 08 and 10) are separately plotted in the inserted boxes with the same scale (no enlargement). The BM boundary located on the bottom (see text) is shown by dashed lines in Figures $11 \mathrm{~b}$ and $11 \mathrm{c}$. 
compared with the most recent compilation of Guyodo and Valet [1999], based on 33 records of relative paleointensity from sediment cores, calibrated to absolute paleointensity from volcanics, and presented as a composite curve spanning the past $800 \mathrm{ka}$. We complemented this curve by the absolute paleointensity variation constrained by archaeomagnetic data [McElhinny and Senanayake, 1982] for the most recent part $(<10 \mathrm{ka}$ ago $)$ and the sedimentary record of Valet and Meynadier [1993] for the part older than $800 \mathrm{ka}$, for the use of subsequent modeling. The paleointensity record (Figure 12a) shows three broad peaks of high paleointensity in the early, middle and late Brunhes, that is a general trend common among most paleointensity records. To derive a model variation of the on-bottom magnetization based on this paleointensity variation, we first modeled the crustal age distribution in the extrusive layer cross section using the lava accumulation model of Schouten and Denham [1979] and defined the magnetization intensity at each point as scaled by the paleointensity at its crustal age. Then the magnetization intensity in shallow part of the magnetic layer was compared with the observed on-bottom variations.

[49] The color map in Figure 12b shows the magnetization distribution model in the extrusive layer obtained by assuming a symmetric spreading. A Gaussian distribution that expresses seafloor spreading and lava accumulation [Schouten and Denham, 1979] with a standard deviation of $0.25 \mathrm{~km}$ is assumed, meaning that $\sim 70 \%$ of the tectonic extension and of the volcanic eruption occurs within $0.5 \mathrm{~km}$ from the axis and more than $95 \%$ within $1 \mathrm{~km}$ from the axis. The magnetization is proportional to the paleointensity of the crustal age at each point, as shown in the right scale labeled "magnetization" in Figure 12a. The model variation of the on-bottom magnetization (top in Figure 12b) was represented by the depth-averaged intensity of the top $20 \mathrm{~m}$ of the magnetic layer, after application of a boxcar filter $256 \mathrm{~m}$ wide representing the length of a segment used for each estimation (see section 4.1.2). Taking the average of the top $50 \mathrm{~m}$ results in little change, except that the variation curve is almost in whole shifted ridgeward by $\sim 100 \mathrm{~m}$.

[50] For comparison with the actual variations, some modifications were made on this symmetric model: for the adaptation to Lines 1 and 2, the eastward ridge jump at 0.45 Ma was included (Figure 12c) according to the evolution model (see section 2.2). As for Line 3, this evolution model seems inapplicable because the graben in the western flank that we interpret as a fossil ridge axis disappears near the segment end; besides, the sea-surface inversion shows an asymmetry in the central anomaly even in the opposite sense there $(\sim 2 \mathrm{~km}$ wider in the east than the west, if the positions of the steepest change in magnetization along Line $3, \mathrm{x}=$ $\sim-8.5$ and $\sim 10.5$, are taken as the BM boundary). As we have no practical way to know the crustal age sequence in the central anomaly, we tentatively adopted a symmetric spreading model calculated using a wider Gaussian distribution (a standard deviation of $1.1 \mathrm{~km}$; Figure 12d), adjusted to the eastern BM boundary on the bottom possibly observed at $\mathrm{x}=$ 12.0 (see section 6.2.1).

\subsubsection{Comparison With Observed Variation}

[51] Figure 13 shows the comparison between the observed on-bottom magnetization variations and the paleointensity-based models. In Figure 13a, not only the similarity observed between close dives in the same cross section (see previous discussion and Figure 11), some agreements are also recognized between dives in Lines 1 and 2: dive 06 (in Line 1) shows a gradual decrease to the west beyond $\mathrm{x}=-7.3$, that is in good agreement with the broad magnetization minimum near $\mathrm{x}=-8.8$ of dives 08 and 10 (in Line 2). Dives 02 and 04 (in Line 1) and dive 17 (in Line 2) consistently show a zone of relatively low magnetizations $(4-13 \mathrm{~A} / \mathrm{m})$ and small variations at $\mathrm{x}=0.9 \sim 3.3$. Despite the incomplete records from deep-sea observations due to data gaps between dives or zones of few reliable estimates, several features of these variations can be correlated with the paleointensity-based models. For example, high magnetizations around the axial zone and flanking lows on both sides are recognized in both Figure 13a and Figure 13b, reflecting the paleointensity high in the late Brunhes and the long-wavelength paleointensity low between the late and middle Brunhes highs. The broad minimum near $x=-8.8$ in Lines 1 and 2 (Figure 13a) is in good agreement with the paleointensity low between the middle and early Brunhes highs. Some reversed of nearly zero magnetizations between strong positives near the eastern BM boundary in Lines 1 and 2 (Figure 13a) may correspond to the short-wavelength dip and flanking two highs in the early Brunhes high, which dip is known as coincident with Delta excursion [Guyodo and Valet, 1999; Valet and Meynadier, 1993; Langereis et al., 1997; Champion et al., 1988], though it remains uncertain due to limited reliable estimates. The most notable difference would be that no signal of the early Brunhes paleointensity high is observed near the western BM boundary (along dive 08 in Figure 13a), supposedly due to the complete lack of reliable estimates in the area.

[52] Although several similarities are found between the observed magnetization variations and the paleointensitybased models, the amplitude of model variations appears small compared with that of the observed variations: the magnetization lows in the model are not less than about half of the magnetization highs. A trial model with increased amplitude, obtained by assuming the magnetization as proportional to (VADM $-4 \times 10^{22} \mathrm{Am}^{2}$ ), as shown by the second right scale labeled "magnetization*" in Figure 12a, was also compared in Figure 13 (dashed lines). The observed variations, typically showing areas of high magnetizations of $\sim 15 \mathrm{~A} / \mathrm{m}$ and lows of $\sim 5 \mathrm{~A} / \mathrm{m}$, seem better match with this model, particularly around the magnetization minimum at $\mathrm{x}=$ -8.8 in Figure 13a. Guyodo and Valet [1999] pointed out that most excursions during the Brunhes epoch coincide with periods of significant intensity drops below a critical field of $4 \times 10^{22} \mathrm{Am}^{2}$ and that a reduction of the present-day dipole intensity by this amount induces the emergence of nondipole components. Because the magnetization in the axial dipole filed direction is assumed in our analysis, the intensity of magnetizations in deviated directions due to the prominent nondipole components during periods of the low dipole filed would not come out in the results. However, if the nondipole components are unstable and change in all directions at a short timescale they would be canceled out without affecting NRM as a mass. If this sediment record of the axial dipole moment variation is correct, it might be speculated that the nondipole filed has some components with enough duration to affect magnetic anomalies, no less than $\sim 0.02 \mathrm{Ma}$ $\left(=256 \mathrm{~m} / 11.8 \mathrm{~km} \mathrm{Ma}^{-1}=\right.$ segment length of magnetization estimation/half spreading rate). Alternatively, it may be more 
(a)

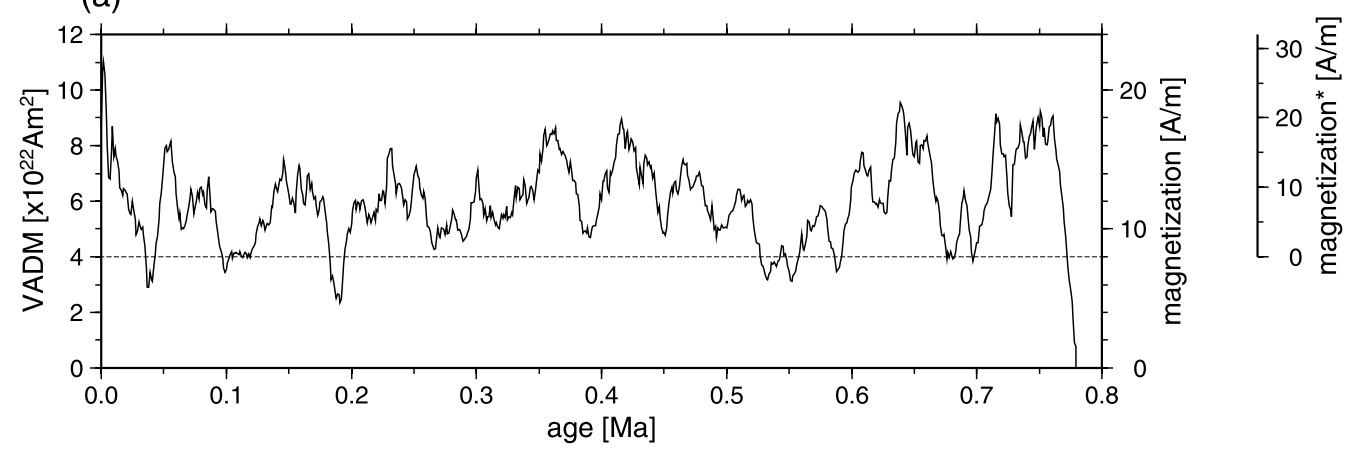

(b)

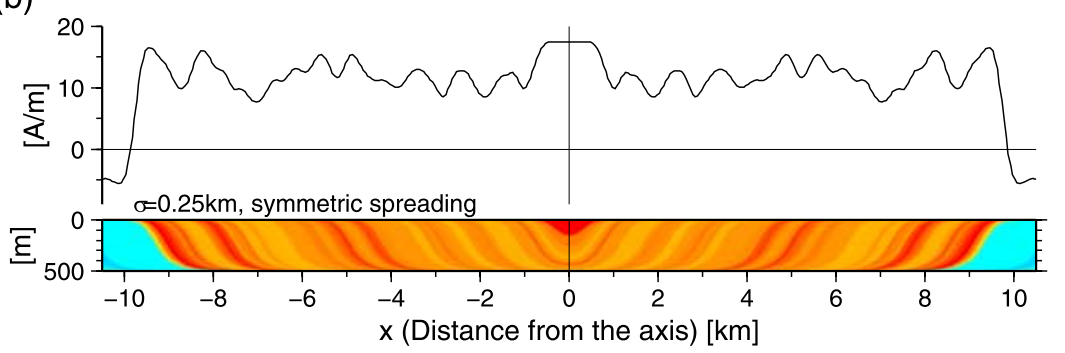

(c)

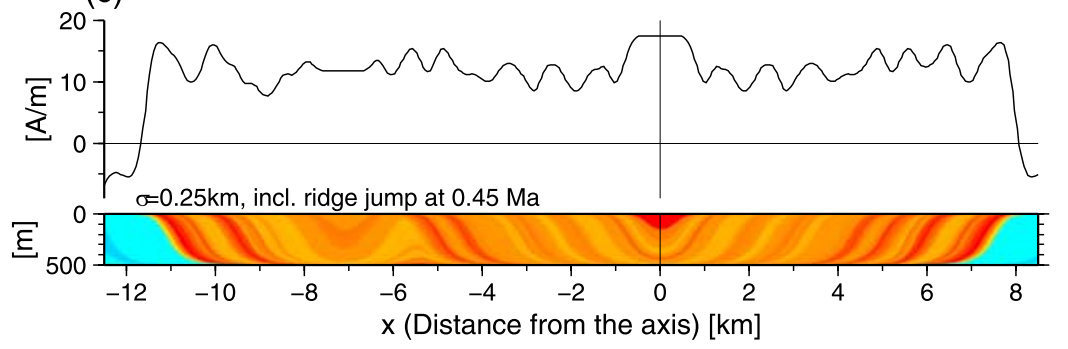

(d)
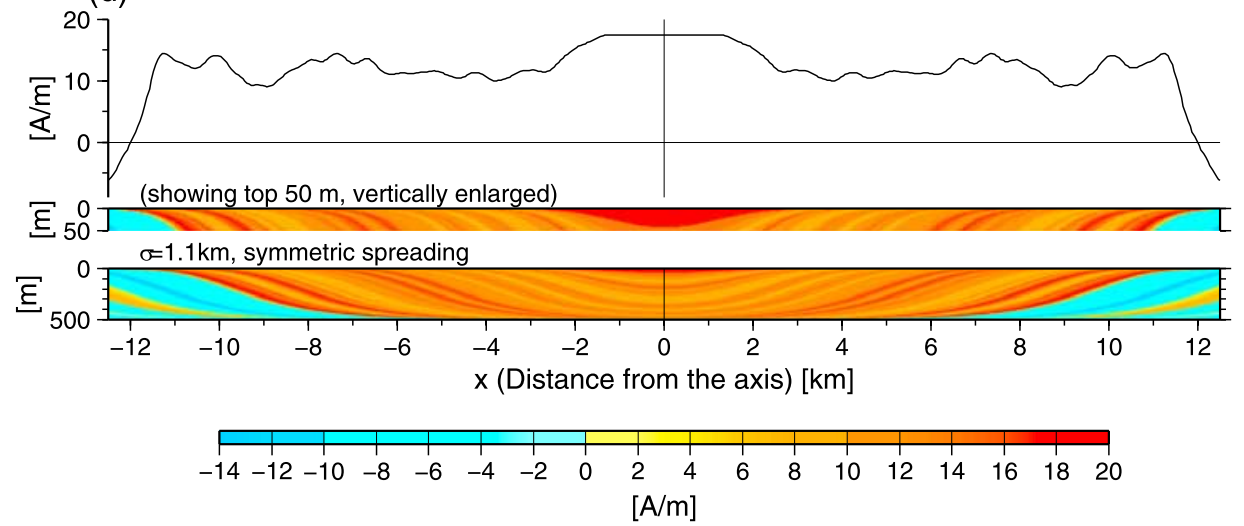

Figure 12. (a) Paleointensity variation during the Brunhes period obtained from deep-sea sediment and archaeomagnetic data [Guyodo and Valet, 1999; McElhinny and Senanayake, 1982]. The record of Valet and Meynadier [1993] is complemented for the part older than $800 \mathrm{ka}$ for the use of subsequent modeling. Age-dependent magnetization was modeled as proportional to the paleointensity (defined by $2.0 \times$ VADM [in $\left.10^{22} \mathrm{Am}^{2}\right]$ ) as shown by the right axis. The horizontal dashed line corresponds to the critical value of $4.0 \times 10^{22} \mathrm{Am}^{2}$, below which directional excursions have been observed [Guyodo and Valet, 1999]. The second right axis, labeled "magnetization*," shows the scale of magnetization with increased amplitude (defined by $4.0 \times\left(\mathrm{VADM}\left[\right.\right.$ in $\left.\left.10^{22} \mathrm{Am}^{2}\right]-4.0\right)$; for the periods of VADM $<4 \times 10^{22} \mathrm{Am}^{2}$ the magnetization is assumed to be zero). See text for details. (b) Models of the magnetization distribution in the extrusive layer (color map) and the on-bottom magnetization variation (a solid curve), calculated using the lava accumulation model of Schouten and Denham [1979] and assuming a symmetric spreading (half rate of $11.8 \mathrm{~km} / \mathrm{Ma}$ ); see text for details. (c) Same as Figure 12b, but including the eastward ridge jump at $0.45 \mathrm{Ma}$. (d) Same as Figure 12b, but calculated using the Gaussian distribution with a wider standard deviation. 


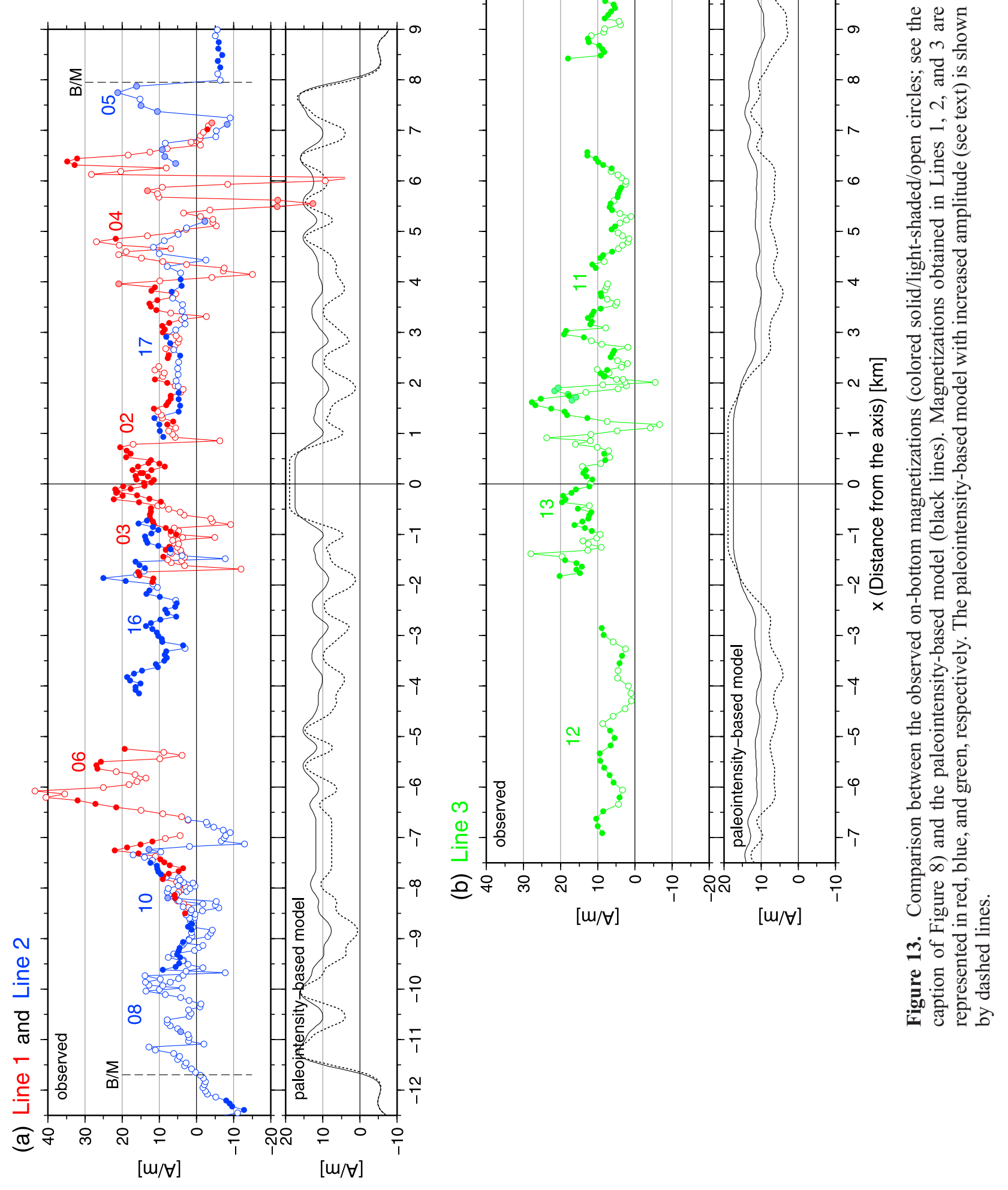


relevant to understand our result is in better agreement with the other records [Schneider and Mello, 1996; Channell et al., 1998; Channell, 1999; Channell and Kleiven, 2000; Channell and Raymo, 2003], at least in the point that they exhibit deeper drop during periods of intensity lows.

\subsubsection{Implications From Sea-Surface Magnetic}

\section{Anomalies}

[53] In accordance with the on-bottom magnetization, the sea-surface inversion also shows the general variation in the central anomaly that can be correlated with the paleointensity variation during the Brunhes epoch: the sea-surface inversion profiles extracted along Lines 1 and 2 (Figure 14a) show the magnetization peaks corresponding to broad paleointensity highs observed in the early, middle and late Brunhes. However, there also exist following differences between these profiles, that should be attributed to other causes than the paleointensity variation: along Line 1, the central anomaly is characterized by three clear peaks (the central one being the $\mathrm{CAMH}$ ) and by gradual transitions at the BM boundaries, whereas it has a flatter and trapezoid shape along Line 2; the Jaramillo anomaly appears stronger along Line 2 than Line 1. In this section, several possible causes for these features were quantitatively examined, considering only the contribution of the extrusive layer as the primary magnetic source at the ridge axis [Dyment and Arkani-Hamed, 1995; Dyment et al., 1997] near the segment center. All the synthetic magnetization profiles in Figures $14 \mathrm{~b}-14 \mathrm{e}$ were obtained as follows: first, sea-surface anomalies caused by a given magnetization distribution (shown together in each of Figures 14b-14e) are computed by the same polygonal approach [Talwani and Heirtzler, 1964] as used in the forward modeling analysis in this study, and then sampled at the same grid spacing to be inverted [Parker and Huestis, 1974] with the same lowpass filter as used in the actual sea-surface inversion (see section 2.1). Other conditions in the inversion calculation (layer thickness and magnetization direction) are also the same as the sea-surface inversion.

\subsubsection{Lava Accumulation Geometry}

[54] It is quite likely at slow spreading ridges like the MAR that tectonic and volcanic activities are varying temporally and spatially rather than proceeding steadily. The effect of variable geometry of accumulated lava is examined by calculating models with various widths of the Gaussian distribution, that defines the seafloor spreading and lava accumulation (Figure 14b). As expected the magnetization curve becomes smoother and less variable as the Gaussian function becomes wider. The smooth transition observed at the $\mathrm{B} / \mathrm{M}$ boundary could be attributed to more diffused distribution of seafloor spreading (faulting) at that time. However, the variations in the central anomaly along Line 1 are considerably larger than even the most variable (and rather unrealistic) model assuming vertical boundaries (Figure 14b, top), indicating other additional causes are needed.

\subsubsection{Topographic Relief}

[55] The difference in topography may possibly affect the inversion results, because the inversion scheme assumes the magnetization to be uniform with depth despite it is true only for the case of vertical boundaries. This effect was evaluated by considering the actual topographic relief both in the forward calculation of anomalies and in the inversion (Figure 14c). The resultant inversion solutions differ slightly, confirming the topographic effect is almost negligible.

\subsubsection{Varying Layer Thickness}

[56] It is worth noting in Figure 14a that areas showing a stronger equivalent magnetization are often located on topographic highs: abyssal hills W1 and E1 in Line 1 are associated with the two magnetization highs ("M") in the central anomaly, and topographic high E2 on the eastern side of Line 2 is associated with a stronger Jaramillo anomaly. If the volcanic activity at the ridge axis has temporal variation and topographic highs represent periods of relatively high activity [Kappel and Ryan, 1986], it may be expected that these topographic highs are underlain by a thicker extrusive layer resulting from the increased activity. To test this hypothesis, we computed models assuming a varying rate of volcanic production: 1.5 times volcanic production is assumed during $0.25-0.45 \mathrm{Ma}$ for Line 1 and $0.9-1.1 \mathrm{Ma}$ for Line 2 corresponding to the generation of the topographic highs, and a half volcanic production is assumed during 0.6-0.8 Ma for both Lines 1 and 2 (Figure 14d). The topographic relief was considered. It is shown that thickened or thinned parts of magnetic layer reasonably simulate the magnetization peaks or the gentle transitions at the BM boundary in the inversion solutions. A difficulty is, however, that recent seismic studies on the MAR reveal a rather constant thickness for the extrusive layer. From their dense seismic reflection survey over the Lucky Strike segment (MAR $37^{\circ} 20^{\prime} \mathrm{N}$ ), Singh et al. [2006] present three across-axis profiles and one along-axis profile which give a maximum factor of 1.3 between the thinner and thicker Layer $2 \mathrm{~A}$ in this area $(0.65$ and 0.5 seconds in travel time, respectively). A seismic refraction survey over the $21^{\circ} 40^{\prime} \mathrm{N}$ segment suggests a similar result [Dannowski et al., 2008]. The seismic data do therefore not show evidence for any large thickness variations of Layer 2A, whereas our model suggests that the thickness of the magnetic layer varies from $250 \mathrm{~m}$ to $750 \mathrm{~m}$, i.e., about threefold, though still remains the possibility that the seismic reflection defining Layer 2A may actually not represent the base of extrusive basalt layer but instead an alteration front as suggested for the seismic boundary separating Layers 2 and 3 [e.g., Detrick et al., 1994; Christeson et al., 2007].

\subsubsection{Petrologic Variations}

[57] An alternative explanation to a thicker magnetic layer under the topographic highs could be a stronger magnetization of the basaltic layer resulting from a higher concentration in iron. Higher iron contents are often associated to the very

\footnotetext{
Figure 14. (a) Sea-surface inversion profiles extracted from Figure 1d along y = 5 (for Line 1) and -2 (for Line 2). Topographic cross sections are shown together by shades. The BM boundary and the Jaramillo chron are indicated by "BM" and "J," and peaks corresponding to the high paleointensity that predominated in the early, middle, and late Brunhes are indicated by "E," "M," and "L," respectively. (b) Model profiles of the sea-surface inversion obtained from the paleointensity-based magnetization distribution and the variable geometry of accumulated lava (see text for details on the calculation). (c) Same as Figure 14b, but the topographic relief is considered in the calculation. The width of the Gaussian function $\sigma$ is $0.25 \mathrm{~km}$. (d) Same as Figure 14c, but assuming thickness variations of the magnetic layer. $\sigma=0.25 \mathrm{~km}$. (e) Same as Figure 14b, but using the intensity model with increased amplitude (see section 6.2.4 and the caption of Figure 12a).
} 
(a) Cross-section of sea-surface inversion
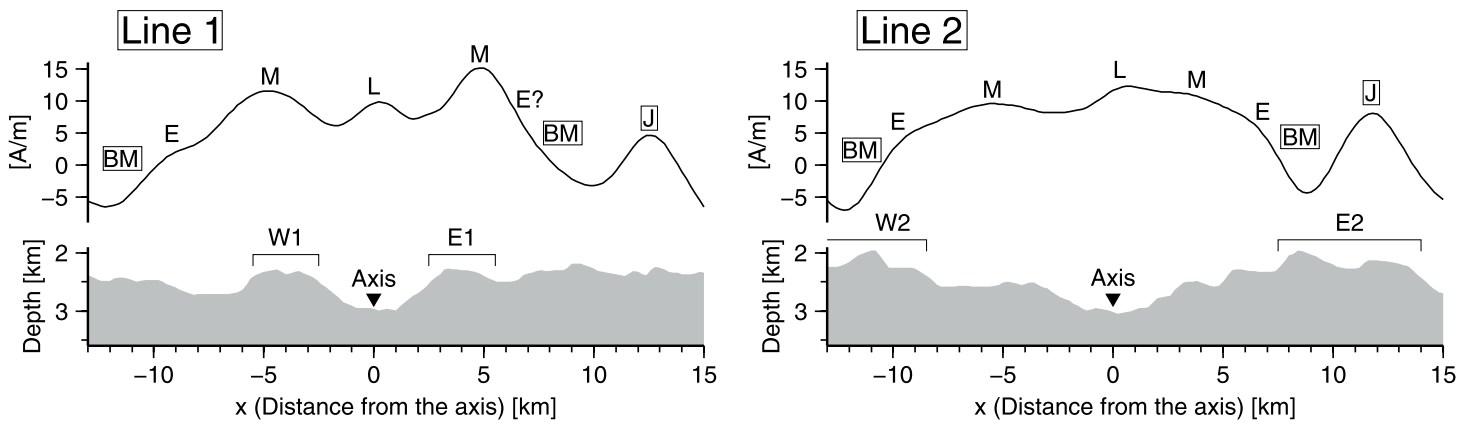

( $B M=B / M$ boundary,$\quad J=$ Jaramillo,$\quad L=$ Late Brunhes,$\quad M=$ Middle Brunhes,$\quad E=$ Early Brunhes )

(b) Lava accumulation geometry

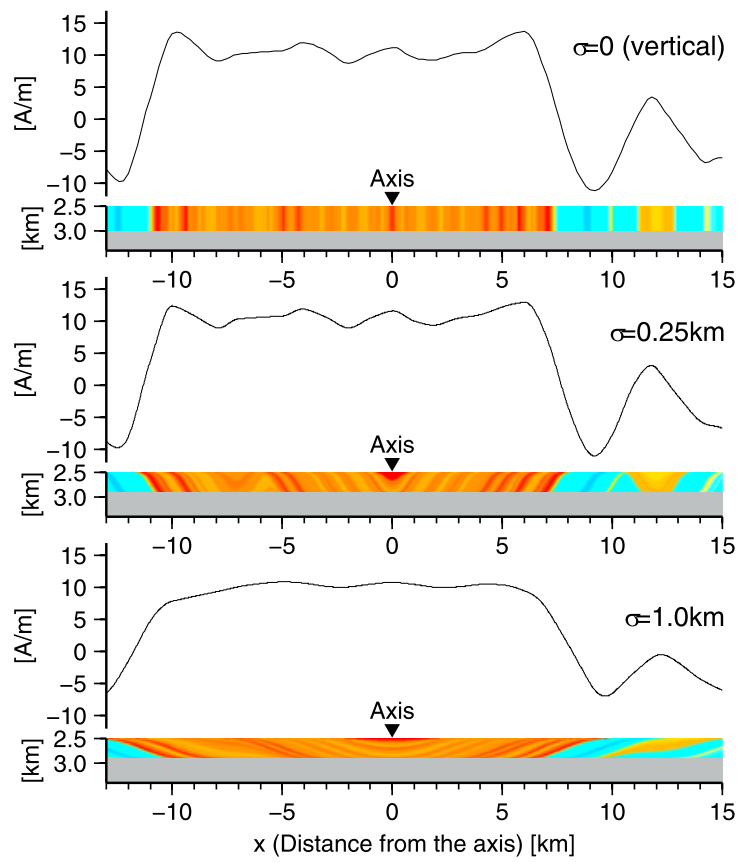

(c) Topographic relief
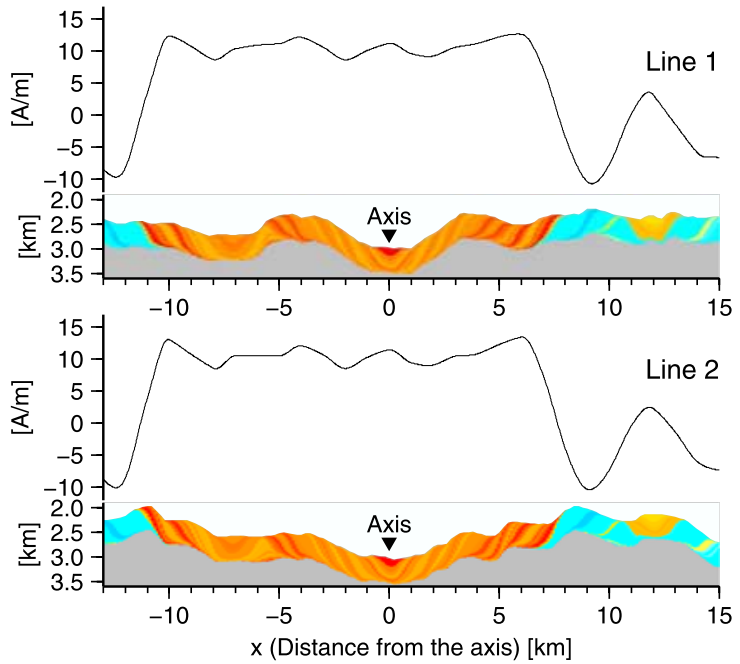

(d) Varying layer thickness
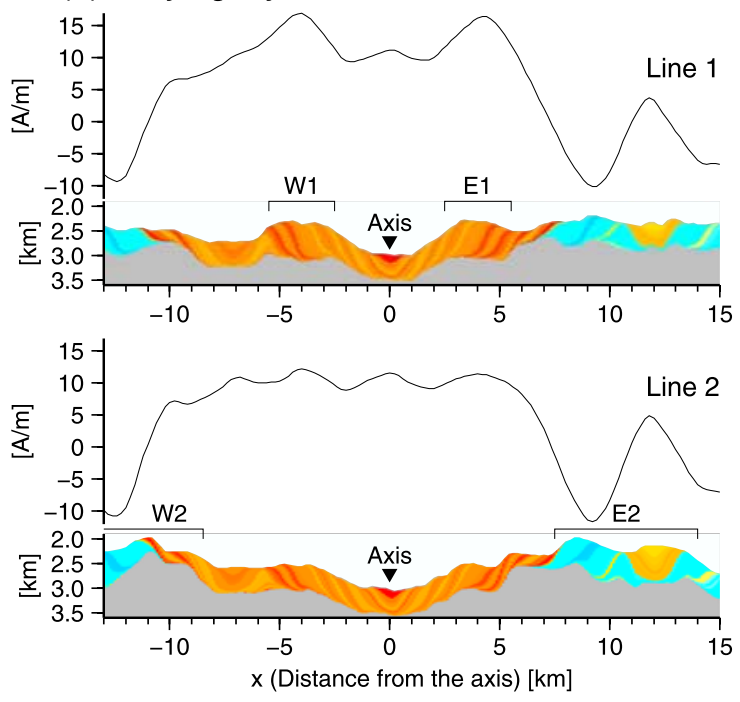

(e) Increased amplitude model
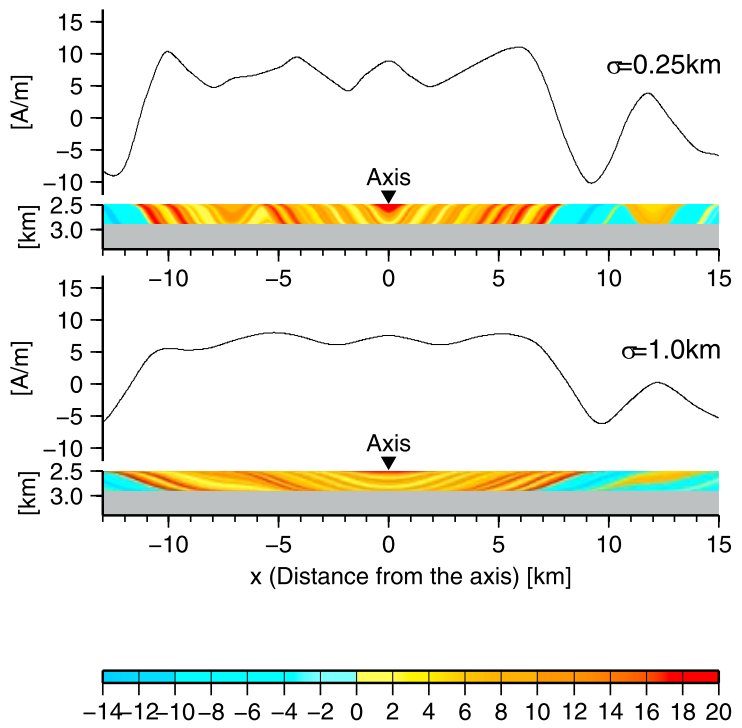
$[\mathrm{A} / \mathrm{m}]$

Figure 14 
magmatic hot spot provinces (e.g., Iceland and the Galapagos [Vogt and Johnson, 1973] and the Azores [Ravilly et al., 1998]) due to the initiation of partial melting at greater depths. A similar effect, although at a smaller scale, may be associated to the high volcanic activity which created the volcanic highs. However, the petrologic analysis of the samples collected during the Nautile dives reveals a remarkable stability of the $\mathrm{Mg}$ number and therefore of the iron content (G. Ceuleneer, personal communication, 2001; G. Ceuleneer, manuscript in preparation, 2009), which discard the hypothesis of petrologic variations as the source of the observed magnetization variations.

\subsubsection{Increased Amplitude Model}

[58] We examined consequences of the intensity model with increased amplitude (see section 6.2.4 and the caption of Figure 12a) on the sea-surface magnetics. It resulted in comparably large variations as observed along Line 1 (Figure $14 \mathrm{e}$ ), suggesting that the variable geometry of lava accumulation could explain the difference between the observed profiles. The main disagreement is that the predicted highs in the early Brunhes are missing in the observed profiles, that would be generally remarked on all the models in Figure 14. The paleointensity peak in the early Brunhes is, however, a rather common feature of most paleointensity records and has been confirmed by marine magnetic anomalies as well [Gee et al., 1996]. This increased amplitude model could give an explanation for the variations in the sea-surface inversion as well as in the on-bottom magnetization (see previous discussion); however, the lack of the probable paleointensity high in our result suggests that other mechanisms are still required, such as the local demagnetization of extrusive rocks or the thinned magnetic layer, though they are not well confirmed in our study.

\section{Conclusions}

[59] The near-bottom magnetic measurements during the 19 dive surveys conducted in the MAR $21^{\circ} 40^{\prime} \mathrm{N}$ segment provides insight into the along-axis and across-axis magnetic structure of the segment. The summarized conclusions from these results are as follows:

[60] 1. The compiled results of the eight dives conducted near the spreading axis at different places in the segment reveal that the axial magnetization intensity is much less variable along the axis than indicated from the sea-surface magnetic anomalies. The high magnetization at segment ends shown in the sea-surface magnetic data is interpreted as representing a thicker magnetic layer than at the segment center. Because many geological and geophysical studies on the slow spreading MAR have suggested thicker crust at segment centers and thinner crust toward segment ends, we suggest that the preferential serpentinization of peridotite is the most plausible cause for the high magnetization near ridge segment ends. If we assume for simplicity a constant thickness $(400 \mathrm{~m})$ and intensity $(13.2 \mathrm{~A} / \mathrm{m})$ for the extrusive layer all along the segment, this model requires about $2.3 \mathrm{~km}$ of serpentinized peridotite bearing an average magnetization of $4 \mathrm{~A} / \mathrm{m}$ to account for the observed along-axis variation in seasurface magnetic anomalies.

[61] 2. The compiled results of the fifteen dives running in the spreading direction show that the across-axis variation of on-bottom magnetization intensity has several features cor- related to the predicted paleointensity variation during the Brunhes epoch. Although magnetization lows are generally correspondent to periods of low paleointensity, they show deeper drop in intensity than predicted from the paleointensity variation and seem to better agree with the model of increased amplitude. The remarkable three peaks in the central anomaly observed in the sea-surface inversion near the segment center also appear to be better explained by this model as representing the paleointensity peaks in the middle and late Brunhes, but the poor appearance of the early Brunhes peak in the observed profiles may still suggest other causes for these tiny wiggles than the paleointensity variation.

[62] Acknowledgments. We are grateful to the scientific party of the TAMMAR cruise, the officers and crew of the R/V Nadir, and the Nautile team for their help during the cruise. We thank H. Fujimoto for his support of this project. We also thank T. Fujiwara, N. Seama, and J. Korenaga for helpful discussions on the processing of the three-component magnetic data. J. Dyment thanks JSPS and Centre National de la Recherche Scientifique (CNRS) for financial support during three visits to Japan. This research was supported by CNRS-INSU and Programme Dorsale in France and by InterRidge Japan in Japan. This is IPGP contribution 2471. GMT-SYSTEM [Wessel and Smith, 1995] was used to process data and make Figures 1-3 and $5-14$.

\section{References}

Blakely, R. J. (1974), Geomagnetic reversals and crustal spreading rates during the Miocene, J. Geophys. Res., 79, 2979-2985.

Bouligand, C., J. Dyment, Y. Gallet, and G. Hulot (2006), Geomagnetic field variations between chrons 33r and 19r (83-41 Ma) from sea-surface magnetic anomaly profiles, Earth Planet. Sci. Lett., 250, 541-560.

Canales, J. P., R. S. Detrick, J. Lin, J. A. Collins, and D. R. Toomey (2000), Crustal and upper mantle seismic structure beneath the rift mountains and across a nontransform offset at the Mid-Atlantic Ridge $\left(35^{\circ} \mathrm{N}\right)$, J. Geophys. Res., 105, 2699-2720.

Cande, S. C., and D. V. Kent (1992), Ultrahigh resolution marine magnetic anomaly profiles: A record of continuous paleointensity variations?, J. Geophys. Res., 97, 15,075-15,083.

Cande, S. C., and J. L. LaBrecque (1974), Behavior of the Earth's paleomagnetic field from small scale marine magnetic anomalies, Nature, 247, $26-28$.

Cannat, M. (1993), Emplacement of mantle rocks in the seafloor at midocean ridges, J. Geophys. Res., 98, 4163-4172.

Cannat, M., et al. (1995), Thin crust, ultramafic exposures, and rugged faulting patterns at the Mid-Atlantic Ridge $\left(22^{\circ}-24^{\circ} \mathrm{N}\right)$, Geology, 23, 49-52.

Carlut, J., and D. V. Kent (2002), Grain-size-dependent paleointensity results from very recent mid-oceanic ridge basalts, J. Geophys. Res., 107(B3), 2049, doi:10.1029/2001JB000439.

Champion, D. E., M. A. Lanphere, and M. A. Kuntz (1988), Evidence for a new geomagnetic reversal from lava flows in Idaho: Discussion of short polarity reversals in the Brunhes and late Matuyama polarity chrons, J. Geophys. Res., 93, 11,667-11,680.

Channell, J. E. T. (1999), Geomagnetic paleointensity and directional secular variation at Ocean Drilling Program (ODP) Site 984 (Bjorn Drift) since 500 ka: Comparisons with ODP Site 983 (Gardar Drift), J. Geophys. Res., 104, 22,937-22,951.

Channell, J. E. T., and H. F. Kleiven (2000), Geomagnetic palaeointensities and astrochronological ages for the Matuyama-Brunhes boundary and the boundaries of the Jaramillo Subchron: Palaeomagnetic and oxygen isotope records from ODP Site 983, Philos. Trans. R. Soc. London, Ser. A, $358,1027-1047$.

Channell, J. E. T., and M. E. Raymo (2003), Paleomagnetic record at ODP Site 980 (Feni Drift, Rockall) for the past 1.2 Myrs, Geochem. Geophys. Geosyst., 4(4), 1033, doi:10.1029/2002GC000440.

Channell, J. E. T., D. A. Hodell, J. McManus, and B. Lehman (1998), Orbital modulation of geomagnetic paleointensity, Nature, 394, 464468.

Christeson, G. L., K. D. McIntosh, and J. A. Karson (2007), Inconsistent correlation of seismic layer $2 \mathrm{a}$ and lava layer thickness in oceanic crust, Nature, 445, 418-421, doi:10.1038/nature05517.

Christie, D. M., and J. M. Sinton (1981), Evolution of abyssal lavas along propagating segments of the Galapagos spreading center, Earth Planet. Sci. Lett., 56, 321-335. 
Dannowski, A., I. Grevemeyer, J. Phipps Morgan, and S. R. Ranero (2008), Crustal structure of a propagating ridge segment from seismic refraction and wide-angle data, Geophys. Res. Abstr., 10, Abstract 1288.

DeMets, C., R. G. Gordon, D. F. Argus, and S. Stein (1994), Effect of recent revisions to the geomagnetic reversal time scale on estimate of current plate motions, Geophys. Res. Lett., 21, 2191-2194.

Detrick, R. S., R. S. White, and G. M. Purdy (1993), Crustal structure of North Atlantic fracture zones, Rev. Geophys., 31, 439-458.

Detrick, R. S., J. Collins, R. Stephen, and S. Swift (1994), In situ evidence for the nature of the seismic layer $2 / 3$ boundary in oceanic crust, Nature, $370,288-290$.

Detrick, R. S., H. D. Needham, and V. Renard (1995), Gravity anomalies and crustal thickness variations along the Mid-Atlantic Ridge between $33^{\circ} \mathrm{N}$ and $40^{\circ} \mathrm{N}$, J. Geophys. Res., 100, 3767-3787.

Dyment, J., and J. Arkani-Hamed (1995), Spreading-rate-dependent magnetization of the oceanic lithosphere inferred from the anomalous skewness of marine magnetic anomalies, Geophys. J. Int., 121, 789-804.

Dyment, J., J. Arkani-Hamed, and A. Ghods (1997), Contribution of serpentinized ultramafics to marine magnetic anomalies at slow and intermediate spreading centers: Insights from the shape of the anomalies, Geophys. J. Int., 129, 691-701.

Gac, S., J. Dyment, C. Tisseau, and J. Goslin (2003), Axial magnetic anomalies over slow-spreading ridge segments: Insights from numerica 3-D thermal and physical modelling, Geophys. J. Int., 154, 618-632.

Gee, J., and D. V. Kent (1994), Variations in layer 2A thickness and the origin of the central anomaly magnetic high, Geophys. Res. Lett., 21, $297-300$.

Gee, J., and D. V. Kent (1997), Magnetization of axial lavas from the southern East Pacific Rise $\left(14^{\circ}-23^{\circ} \mathrm{S}\right)$ : Geochemical controls on magnetic properties, J. Geophys. Res., 102, 24,873-24,886.

Gee, J., D. A. Schneider, and D. V. Kent (1996), Marine magnetic anomalies as recorders of geomagnetic intensity variations, Earth Planet. Sci. Lett., 144, 327-335.

Gee, J. S., S. C. Cande, J. A. Hildebrand, K. Donnelly, and R. L. Parker (2000), Geomagnetic intensity variations over the past $780 \mathrm{kyr}$ obtained from near-seafloor magnetic anomalies, Nature, 408, 827-832.

Gente, P., R. A. Pockalny, C. Durand, C. Deplus, M. Maia, G. Ceuleneer, C. Mevel, M. Cannat, and C. Laverne (1995), Characteristics and evolution of the segmentation of the Mid-Atlantic Ridge between $20^{\circ} \mathrm{N}$ and $24^{\circ} \mathrm{N}$ during the last 10 million years, Earth Planet. Sci. Lett., 129, 55-71.

Gente, P., G. Ceuleneer, O. Dauteuil, J. Dyment, C. Honsho, C. Laverne, C. Le Turdu, N. C. Mitchell, M. Ravilly, and R. Thibaud (1996), On- and off-axis submersible investigations on a highly magmatic segment of the Mid-Atlantic Ridge $\left(21^{\circ} 40^{\prime} \mathrm{N}\right)$ : The TAMMAR cruise, InterRidge News, 5 , $27-31$.

Gràcia, E., D. Bideau, R. Hekinian, Y. Lagabrielle, and L. M. Parson (1997), Along-axis magmatic oscillations and exposures of ultramafic rocks in a second-order segment of the Mid-Atlantic Ridge $\left(33^{\circ} 43^{\prime} \mathrm{N}\right.$ to $\left.34^{\circ} 07^{\prime} \mathrm{N}\right)$, Geology, 25, 1059-1062.

Grindlay, N. R., P. J. Fox, and P. R. Vogt (1992), Morphology and tectonics of the Mid-Atlantic Ridge $\left(25^{\circ}-27^{\circ} 30^{\prime} \mathrm{N}\right)$ from SeaBeam and magnetic data, J. Geophys. Res., 97, 6983-7010.

Guspi, F. (1987), Frequency-domain reduction of potential field measurements to a horizontal plane, Geoexploration, 24, 87-98.

Guyodo, Y., and J.-P. Valet (1999), Global changes in intensity of the Earth's magnetic field during the past $800 \mathrm{kyr}$, Nature, 399, 249-252.

Hamano, Y., M. M. Bina, and K. Krammer (1990), Paleomagnetism of the serpentinized peridotite from ODP Hole 670A, Proc. Ocean Drill. Program Sci. Results, 106/109, 257-262.

Harrison, C. G. A. (1987), Marine magnetic anomalies - The origin of the stripes, Annu. Rev. Earth Planet. Sci., 15, 505-543.

Hey, R. N., M. C. Kleinrock, S. P. Miller, T. M. Atwater, and R. C. Searle (1986), Sea beam/deep-tow investigation of an active oceanic propagating rift system, Galapagos $95.5^{\circ} \mathrm{W}$, J. Geophys. Res., 91, 3369-3393.

Hooft, E. E. E., R. S. Detrick, J. Lin, J. A. Collins, and D. R. Toomey (2000), Crustal and mantle seismic structure beneath the rift mountains and across a non-transform offset at the Mid-Atlantic Ridge $\left(35^{\circ} \mathrm{N}\right)$, J. Geophys. Res., 105, 8205-8226.

Horen, H., and C. Fleutelot (1998), Highly magnetized and differentiated basalts at the $18-19^{\circ} \mathrm{S}$ propagating spreading centre in the North Fiji Basin, Mar. Geophys. Res., 20, 129-137.

Hussenoeder, S. A., M. A. Tivey, and H. Schouten (1995), Direct inversion of potential fields from an uneven track with application to the MidAtlantic Ridge, Geophys. Res. Lett., 22, 3131-3134.

Hussenoeder, S. A., M. A. Tivey, H. Schouten, and R. C. Searle (1996), Near-bottom magnetic survey of the Mid-Atlantic Ridge axis, $24^{\circ}-$ $24^{\circ} 40^{\prime} \mathrm{N}$ : Implications for crustal accretion at slow spreading ridges, J. Geophys. Res., 101, 22,051-22,069.
Irving, E., W. A. Robertson, and F. Aumento (1970), The Mid-Atlantic Ridge near $45^{\circ} \mathrm{N}, \mathrm{VI}$, Remanent intensity, susceptibility and iron content of dredge sample, Can. J. Earth Sci., 7, 226-238.

Isezaki, N. (1986), A new shipboard three-component magnetometer, Geophysics, 51, 1992-1998.

Johnson, H. P., and T. Atwater (1977), Magnetic study of basalts from the Mid-Atlantic Ridge crest near lat $37^{\circ}$ N, Geol. Soc. Am. Bull., 88, 637-647.

Johnson, H. P., and M. A. Tivey (1995), Magnetic properties of zero-age oceanic crust: A new submarine lava flow on the Juan de Fuca ridge, Geophys. Res. Lett., 22, 175-178.

Juteau, T., M. Cannat, and Y. Lagabrielle (1990), Serpentinized peridotites in the upper oceanic crust away from transform zones: A comparison of the results of previous DSDP and ODP legs, Proc. Ocean Drill. Program Sci. Results, 106/109, 303-308.

Kappel, E. S., and W. B. Ryan (1986), Volcanic episodicity and a non-steady state rift valley along Northeast Pacific spreading centers: Evidence from SeaMARC I, J. Geophys. Res., 91, 13,925-13,940.

Kent, D. V., and N. D. Opdyke (1977), Palaeomagnetic field intensity variation recorded in a Brunhes epoch deep-sea sediment core, Nature, 266, 156-159.

Klitgord, K. D. (1976), Sea-floor spreading: The central anomaly magnetization high, Earth Planet. Sci. Lett., 29, 201-209.

Langereis, C. G., M. L. Dekkers, G. J. de Lange, M. Paterne, and P. J. M. Santvoort (1997), Magnetostratigraphy and astronomical calibration of the last 1.1 Myr form an eastern Mediterranean piston core and dating of short events in the Brunhes, Geophys. J. Int., 129, 75-94.

Lawson, K., R. C. Searle, J. A. Pearce, P. Browning, and P. Kempton (1996), Detailed volcanic geology of the MARNOK area, Mid-Atlantic Ridge north of Kane transform, in Tectonic, Magmatic, Hydrothermal and Biological Segmentation of Mid-Ocean Ridges, edited by C. J. MacLeod, P. A. Tyler, and C. L. Walker, Geol. Soc. Spec. Publ., 118, 61-102.

Lee, S.-M., S. C. Solomon, and M. A. Tivey (1996), Fine-scale crustal magnetization variations and segmentation of the East Pacific Rise, $9^{\circ} 10^{\prime}-9^{\circ} 50^{\prime} \mathrm{N}$, J. Geophys. Res., 101, 22,033-22,050.

Lin, J., and J. Phipps Morgan (1992), The spreading rate dependence of three-dimensional mid-ocean ridge gravity structure, Geophys. Res. Lett., $19,13-16$

Lin, J., G. M. Purdy, H. Schouten, J. C. Sempere, and C. Zervas (1990), Evidence for focused magmatic accretion along the Mid-Atlantic Ridge, Nature, 344, 627-632.

Macdonald, K. C. (1977), Near-bottom magnetic anomalies, asymmetric spreading, oblique spreading, and tectonics of the Mid-Atlantic Ridge near lat $37^{\circ} \mathrm{N}$, Geol. Soc. Am. Bull., 88, 541-555.

Macdonald, K. C., S. P. Miller, S. P. Huestis, and F. N. Spiess (1980), Three-dimensional modeling of a magnetic reversal boundary from inversion of deep-tow measurements, J. Geophys. Res., 85, 3670-3680

Macdonald, K. C., S. P. Miller, B. P. Luyendyk, T. M. Atwater, and L. Shure (1983), Investigation of a Vine-Matthews magnetic lineation from a submersible: The source and character of marine magnetic anomalies, J. Geophys. Res., 88, 3403-3418.

Macdonald, K. C., P. J. Fox, L. J. Perram, M. F. Eisen, R. M. Haymon, S. P. Miller, S. M. Carbotte, M. H. Cormier, and A. N. Shor (1988), A new view of the mid-ocean ridge from the behaviour of ridge-axis discontinuities, Nature, 335, 217-225.

Maia, M., and P. Gente (1998), Three-dimensional gravity and bathymetry analysis of the Mid-Atlantic Ridge between $20^{\circ} \mathrm{N}$ and $24^{\circ} \mathrm{N}$ : Flow geometry and temporal evolution of the segmentation, J. Geophys. Res., 103, $951-974$.

McElhinny, M. W., and W. E. Senanayake (1982), Variations in the geomagnetic dipole: 1, The past 50,000 years, J. Geomagn. Geoelectr., 34, 39-51.

McKenzie, D., and C. Bowin (1976), The relationship between bathymetry and gravity in the Atlantic Ocean, J. Geophys. Res., 81, 1903-1915.

Nazarova, K. A. (1994), Serpentinized peridotites as a possible source for oceanic magnetic anomalies, Mar. Geophys. Res., 16, 455-462.

Oufi, O., M. Cannat, and H. Horen (2002), Magnetic properties of variably serpentinized abyssal peridotites, J. Geophys. Res., 107(B5), 2095, doi:10.1029/2001JB000549.

Pariso, J. E., J.-C. Sempere, and C. Rommevaux (1995), Temporal and spatial variations in crustal accretion along the Mid-Atlantic Ridge $\left(29^{\circ}-\right.$ $31^{\circ} 30^{\prime} \mathrm{N}$ ) over the last $11 \mathrm{Myr}$ : Implications from a three-dimensional gravity study, J. Geophys. Res., 100, 17,781-17,794.

Pariso, J. E., C. Rommevaux, and J. C. Sempere (1996), Three-dimensional inversion of marine magnetic anomalies: Implications for crustal accretion along the Mid-Atlantic Ridge $\left(28^{\circ}-31^{\circ} 30^{\prime} \mathrm{N}\right)$, Mar. Geophys. Res., $18,85-101$

Parker, R. L., and S. P. Huestis (1974), The inversion of magnetic anomalies in the presence of topography, J. Geophys. Res., 79, 1587-1593.

Pilkington, M., and W. E. S. Urquhart (1990), Reduction of potential field data to a horizontal plane, Geophysics, 55, 549-555. 
Pockalny, R. A., A. Smith, and P. Gente (1995), Spatial and temporal variability of crustal magnetization of a slowly spreading ridge: Mid-Atlantic Ridge $\left(20^{\circ}-24^{\circ} \mathrm{N}\right)$, Mar. Geophys. Res., 17, 301-320.

Pouliquen, G., Y. Gallet, P. Patriat, J. Dyment, and C. Tamura (2001), A geomagnetic record over the last 3.5 million years from deep-tow magnetic anomaly profiles across the Central Indian Ridge, J. Geophys. Res., 106, 10,941-10,960.

Ravilly, M. (1999), Ètude de l'anomalie magnètique axiale le long de la ride mèdio-atlantique: Implications sur les processus de l'accrètion et les variations temporelles du champ gèomagnètique, Ph.D. thesis, Univ. Brest, Brest, France.

Ravilly, M., J. Dyment, P. Gente, and R. Thibaud (1998), Axial magnetic anomaly amplitude along the Mid-Atlantic Ridge between $20^{\circ} \mathrm{N}$ and $40^{\circ}$ N, J. Geophys. Res., 103, 24,201-24,221.

Ravilly, M., H. Horen, M. Perrin, J. Dyment, P. Gente, and H. Guillou (2001), NRM intensity of altered oceanic basalts across the MAR $\left(21^{\circ} \mathrm{N}, 0-1.5 \mathrm{M} . \mathrm{y}.\right)$ : A record of geomagnetic paleointensity variations?, Geophys. J. Int., 145, 401-422.

Rea, D. K., and R. J. Blakely (1975), Short wavelength magnetic anomalies in a region of rapid sea-floor spreading, Nature, 255, 126-128.

Sayanagi, K., H. Fujimoto, K. Tamaki, T. Fujiwara, H. Murakami, and K. Minoshima (1995), Development of new versatile deep-sea threecomponent magnetometer system, J. Jpn. Soc. Mar. Surv. Tech., 6, $21-32$.

Schneider, D. A., and G. A. Mello (1996), A high-resolution marine sedimentary record of geomagnetic intensity during the Brunhes Chron, Earth Planet. Sci. Lett., 144, 297-314.

Schouten, H., and C. R. Denham (1979), Modeling of the oceanic magnetic source layer, in Deep Drilling Results in the Atlantic Ocean: Ocean Crust, Maurice Ewing Ser, vol. 2, pp. 151-159, AGU, Washington, D. C.

Schouten, H., M. A. Tivey, D. J. Fornari, and J. R. Cochran (1999), Central anomaly magnetization high: Constraints on the volcanic construction and architecture of seismic layer $2 \mathrm{~A}$ at a fast-spreading mid-ocean ridge, the EPR at $9^{\circ} 30^{\prime} \mathrm{N}-50^{\prime} \mathrm{N}$, Earth Planet. Sci. Lett., 169, 37-50.

Sempere, J.-C. (1991), High-magnetization zones near spreading center discontinuities, Earth Planet. Sci. Lett., 107, 389-405.

Shah, A. K., M.-H. Cormier, W. B. F. Ryan, W. Jin, J. Sinton, E. Bergmanis, J. Carlut, A. Bradley, and D. Yoerger (2003), Episodic dike swarms inferred from near-bottom magnetic anomaly maps at the southern East Pacific Rise, J. Geophys. Res., 108(B2), 2097, doi:10.1029/2001JB000564 Singh, S. C., W. C. Crawford, H. Carton, T. Seher, V. Combier, M. Cannat, J. P. Canales, D. Düsünür, J. Escartin, and J. M. Miranda (2006), Discovery of a magma chamber and faults beneath a Mid-Atlantic Ridge hydrothermal field, Nature, 442, 1029-1032, doi:10.1038/nature05105.

Talwani, M., and J. R. Heirtzler (1964), Computation of magnetic anomalies caused by two-dimensional structures of arbitrary shape, in Computers in the Mineral Industries, edited by G. A. Parks, pp. 464-480, Stanford Univ. Publ. of the Geol. Sci., Stanford, Calif.

Talwani, M., C. C. Windisch, and M. G. Langseth (1971), Reykjanes Ridge crest: A detailed geophysical study, J. Geophys. Res., 76, 473-517.

Thibaud, R., P. Gente, and M. Maia (1998), A systematic analysis of the Mid-Atlantic Ridge morphology and gravity between $15^{\circ} \mathrm{N}$ and $40^{\circ} \mathrm{N}$ : Constraints of the thermal structure, J. Geophys. Res., 103, 24,22324,243 .

Tivey, M. A. (1994), Fine-scale magnetic anomaly field over the southern Juan de Fuca Ridge: Axial magnetization low and implications for crusta structure, J. Geophys. Res., 99, 4833-4855.

Tivey, M. A., and H. P. Johnson (1987), The central anomaly magnetic high: Implications for ocean crust construction and evolution, J. Geophys. Res., 92, 12,685-12,694.

Tivey, M. A., and H. P. Johnson (1993), Variations in oceanic crustal structure and implications for the fine-scale magnetic anomaly signal, Geophys. Res. Lett., 20, 1879-1882.

Tivey, M. A., and H. P. Johnson (2002), Crustal magnetization reveals subsurface structure of Juan de Fuca Ridge hydrothermal vent fields, Geology, 30, 979-982.
Tivey, M. A., and B. E. Tucholke (1998), Magnetization of 0-29 Ma ocean crust on the Mid-Atlantic Ridge, $25^{\circ} 30^{\prime}$ to $27^{\circ} 10^{\prime} \mathrm{N}$, J. Geophys. Res. $103,17,807-17,826$.

Tivey, M. A., P. A. Rona, and H. Schouten (1993), Reduced crustal magnetization beneath the active sulfide mound, TAG hydrothermal field, Mid-Atlantic Ridge at $26^{\circ} \mathrm{N}$, Earth Planet. Sci. Lett., 115, 101-105.

Toft, P. B., J. Arkani-Hamed, and S. E. Haggerty (1990), The effects of serpentinization on density and magnetic susceptibility: A petrophysical model, Phys. Earth Planet. Inter., 65, 137-157.

Tolstoy, M., A. J. Harding, and J. A. Orcutt (1993), Crustal thickness on the Mid-Atlantic Ridge: Bull's eye gravity anomalies and focused accretion, Science, 262, 726-729.

Valet, J.-P., and L. Meynadier (1993), Geomagnetic field intensity and reversals during the past four million years, Nature, 366, 234-238.

Vine, F. J., and D. H. Matthews (1963), Magnetic anomalies over oceanic ridges, Nature, 199, 947-949.

Vogt, P. R. (1979), Amplitudes of oceanic magnetic anomalies and the chemistry of oceanic crust: Synthesis and review of magnetic telechemistry, Can. J. Earth. Sci., 16, 2236-2262.

Vogt, P. R., and G. R. Byerly (1976), Magnetic anomalies and basalt composition in the Juan de Fuca-Gorda Ridge area, Earth Planet. Sci. Lett., $33,185-207$

Vogt, P. R., and G. L. Johnson (1973), Magnetic telechemistry of oceanic crust?, Nature, 245, 373-375.

Watts, A. B. (1978), An analysis of isostasy in the world's oceans: 1. Hawaiian-Emperor Seamount Chain, J. Geophys. Res., 83, 5989-6004

Weiland, C. M., and K. C. Macdonald (1993), Variation of crustal magnetization at the Mid-Atlantic Ridge $31^{\circ}-36^{\circ} \mathrm{S}$ : Rock magnetism and 3-dimensional inversion, Eos Trans. $A G U$, 74(16), Spring Meet. Suppl., 304.

Weiland, C. M., K. C. Macdonald, and N. R. Grindlay (1996), Ridge segmentation and the magnetic structure of the Southern Mid-Atlantic Ridge $26^{\circ} \mathrm{S}$ and $31^{\circ}-35^{\circ} \mathrm{S}$ : Implication for magmatic processes at slow spreading centers, J. Geophys. Res., 101, 8055-8073.

Wessel, P., and W. H. F. Smith (1995), New version of the generic mapping tools released, Eos Trans. $A G U, 76,329$

Williams, C. M., M. A. Tivey, H. Schouten, and D. J. Fornari (2008), Central Anomaly Magnetization High documentation of crustal accretion along the East Pacific Rise $\left(9^{\circ} 55^{\prime}-9^{\circ} 25^{\prime} \mathrm{N}\right)$, Geochem. Geophys. Geosyst., 9, Q04015, doi:10.1029/2007GC001611.

Wooldridge, A. L., S. E. Haggerty, P. A. Rona, and C. G. A. Harrison (1990), Magnetic properties and opaque mineralogy of rocks from selected seafloor hydrothermal sites at oceanic ridges, J. Geophys. Res., 95 , $12,351-12,374$

Wooldridge, A. L., C. G. A. Harrison, S. E. Haggerty, M. A. Tivey, P. A. Rona, and H. Schouten (1992), Magnetic modeling near selected areas of hydrothermal activity on the Mid-Atlantic and Gorda Ridges, J. Geophys. Res., 97, 10,911-10,926.

Yamazaki, T., N. Ioka, and N. Eguchi (1995), Relative paleointensity of the geomagnetic field during the Brunhes Chron, Earth Planet. Sci. Lett., $136,525-540$.

Zhou, W., R. Van der Voo, D. Peacor, and Y. Zhang (2000), Variable Ticontent and grain size of titanomagnetite as a function of cooling rate in very young MORB, Earth Planet. Sci. Lett., 179, 9-20.

J. Dyment, Institut de Physique du Globe de Paris, UMR7154, CNRS, 4 place Jussieu, F-75252 Paris CEDEX 05, France.

P. Gente, Domaines Océaniques, UMR6538, Institut Universitaire Européen de la Mer, Université de Brest, CNRS, 1 place Nicolas Copernic, F-29280 Plouzané, France.

C. Honsho and K. Tamaki, Frontier Research Center for Energy and Resources, School of Engineering, University of Tokyo, Engineering Building No. 4, 7-3-1 Hongo, Bunkyo-ku, Tokyo 113-8656, Japan. (honsho@frcer.t.utokyo.ac.jp)

H. Horen, Dynamique des Systèmes Anthropisés, JE2532, Université Picardie Jules Verne, 33 rue Saint-Leu, F-80039 Amiens, France.

M. Ravilly, CREOCEAN, Rue Charles Tellier, F-17000 La Rochelle, France. 